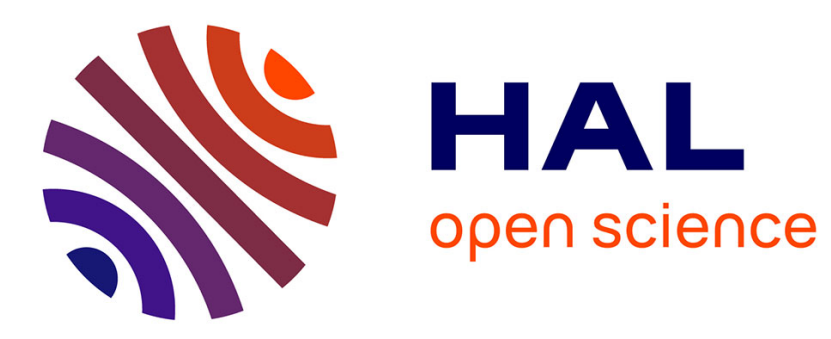

\title{
A comprehensive accretion model for glaciated icing conditions
}

P. Trontin, P. Villedieu

\section{To cite this version:}

P. Trontin, P. Villedieu. A comprehensive accretion model for glaciated icing conditions. International Journal of Multiphase Flow, 2018, pp.1-10. 10.1016/j.ijmultiphaseflow.2018.06.023 hal-01870916

\section{HAL Id: hal-01870916 https://hal.science/hal-01870916}

Submitted on 10 Sep 2018

HAL is a multi-disciplinary open access archive for the deposit and dissemination of scientific research documents, whether they are published or not. The documents may come from teaching and research institutions in France or abroad, or from public or private research centers.
L'archive ouverte pluridisciplinaire HAL, est destinée au dépôt et à la diffusion de documents scientifiques de niveau recherche, publiés ou non, émanant des établissements d'enseignement et de recherche français ou étrangers, des laboratoires publics ou privés. 


\title{
A comprehensive accretion model for glaciated icing conditions
}

\author{
P. Trontin ${ }^{\mathrm{a}, *}$, P. Villedieu ${ }^{\mathrm{a}}$ \\ ${ }^{a}$ ONERA / DMPE, Université de Toulouse \\ F-31055 Toulouse - France
}

\begin{abstract}
Icing has been identified as a major hazard for aviation safety since the beginning of aeronautical engineering. This paper is focused on ice crystal icing (ICI) which is related to ice accretion for an aircraft in flight in the presence of ice particles. Liquid water is necessary for the ice crystals to stick to the walls of the internal components of an aircraft engine. Emphasis is put on the glaciated conditions where the required liquid water comes from the melting of the ice crystals themselves when they enter a warm environment (the engine core). ICI represents an important concern for flight safety in addition to classical supercooled water icing where the accreted ice only derives from the instantaneous freezing of supercooled liquid droplets when they hit an obstacle. A semi-empirical model which accounts for the influence of the ice crystals on the mass and momentum balance equations is proposed. It accounts for the liquid transport in the porous ice layer and for the ice crystal sticking efficiency. The physics is extremely complicated and not completely understood. Therefore, several adjustable parameters are used in the model. However, the model predictions agree well with the existing experimental data. In particular, the model is able to predict typical conical accretion shapes that are never found in classical supercooled water icing conditions. Moreover, the influence of the ice crystal melting ratio on the accretion shapes is properly accounted for.
\end{abstract}

Keywords: Ice crystal icing, glaciated conditions, accretion model.

\footnotetext{
*Corresponding author: pierre.trontin@onera.fr
} 


\section{Introduction}

Icing has been identified as a major hazard for aviation safety since the beginning of aeronautical engineering. Liquid water freezing may cause performance degradation such as loss of lift and increased drag due to local ice accumulation, erroneous flight parameters displayed inside the cockpit due to probe clogging or in the most severe cases loss of engine thrust, engine damage and even engine flame-out.

Among the possible causes of icing for aircraft in flight, supercooled water icing (SWI) where ice accretion is the result of the impact of supercooled droplets, can be considered as the primary hazard (Fluid Dynamics Panel Working Group 20, 1997; Civil Aviation Authority of New Zealand, 2000). Supercooling is a thermodynamically unstable state for liquid droplets where a phase change to solid state can be initiated when the droplets hit an obstacle like a wing, a probe or a blade inside an engine. Supercooled droplets appear in the atmosphere at low temperatures in the range of $-40{ }^{\circ} \mathrm{C}$ to $0{ }^{\circ} \mathrm{C}$.

Icing may also be the result of impact and deposition of ice particles. Beside supercooled water icing, ice crystal icing (ICI) represents as well a severe threat for flight safety (Mason et al., 2006). Ice crystals are found in (sub)-tropical regions (Bravin et al., 2015) in the vicinity of convective clouds at the altitude of $\sim 7000 \mathrm{~m}$ where supercooled droplets usually do not exist. In theses regions of deep convective systems, engine rollback, flameout or stall and damage to downstream compressors from shed ice have been observed. As reported by Mason et al. (2006), the power-loss incidents that have occured since 1990 result from atmospheric ice crystals entering the engine core.

With no liquid water, the ice particles do not adhere to cold airframe surfaces and bounce off. Regarding the presence of liquid water which is necessary for the ice crystals to stick, two origins are possible. On the one hand, the liquid water may come from supercooled liquid droplets mixed with the ice cores in mixed phase clouds at atmospheric temperatures above $-40{ }^{\circ} \mathrm{C}$. These atmospheric conditions are referred to "mixed phase conditions" and are encountered at temperatures below $0{ }^{\circ} \mathrm{C}$. On the other hand, the liquid water may come from the melted part of the ice crystals themselves. This regime is referred to "glaciated conditions" and is often associated to engine conditions characterized by a wet bulb temperature above the freezing point. Both glaciated and mixed phase conditions occur in convective clouds and 
have been present during engine power-loss and damage events (Mason et al., 2006).

Among the experiments performed below $0{ }^{\circ} \mathrm{C}$ at mixed phase conditions, ice accretion tests have been performed at the COX icing research tunnel (Al-Khalil et al., 2003; Miller et al., 1997) on a NACA0012 airfoil. Low total water contents (from $0.3 \mathrm{~g} . \mathrm{m}^{-3}$ to $1.4 \mathrm{~g} . \mathrm{m}^{-3}$ ) have been investigated. Similarly to supercooled water icing, glaze and rime ice shapes have been observed. Since 1990 and due to the engine powerloss events (Mason et al., 2006), the NASA Propulsion System Laboratory (PSL) has been upgraded to have a capability for ice crystal generation for engine research activities under simulated altitude conditions (Goodwin and Dischinger, 2014). Ice particles are generated by the spray bar technique where the injected liquid droplets are forced to freeze to generate ice particles. The shaved ice method has been dropped since it appeared impractical for such a large facility (Griffin et al., 2014). Mixed phase conditions have been tested experimentally at RATFac from NRC with an hemispheric test model (Currie and Fuleki, 2016). For the coldest conditions, with a wet bulb temperature from $-8{ }^{\circ} \mathrm{C}$ to $-5.5{ }^{\circ} \mathrm{C}$, the right end of the plateau (see below) has not been exhibited since accretion remains possible with supercooled liquid droplets only. For low melting ratios $(\sim 14.4 \%)$, accretion shapes with a constant cone angle of $\sim 90^{\circ}$ has been observed (Currie and Fuleki, 2016). At higher melting ratios, the cone angle has become smaller as observed for past experiments where the wet bulb temperature was higher than the freezing point (glaciated conditions, see below). A detailed review dedicated to the experimental studies in mixed phase conditions can be found in Baumert et al. (2018).

Regarding the glaciated conditions, the melt ratio of the ice particles is driven by the local relative humidity or, which is equivalent, by the wet bulb temperature. The importance of the wet bulb temperature as primary scaling factor in matching accretion shapes has been demonstrated by Currie et al. (2013) at RATFac for two different pressures $(34.5 \mathrm{kPa}$ and $69 \mathrm{kPa})$. Both Mach number and total water content are being held constant. The wet bulb temperature has little influence on accretion growth beyond its effect on the particle melting (Currie et al., 2013). For the icing conditions where the melting ratio is adjusted by the addition of supplemental supercooled liquid water, similar ice accretions are obtained in comparison with conditions with natural melting of the ice crystals (Currie et al., 2013). For melting ratios ranging from 5 to $35 \%$, significant ice accretion rates have been reported by NASA and NRC studies at RATFac (Currie et al., 2012, 2013, 2014). 
This "plateau" (see Fig. 1) is characterized by a left and a right boundary where icing severity decreases strongly. At low melting ratios (left limit) the

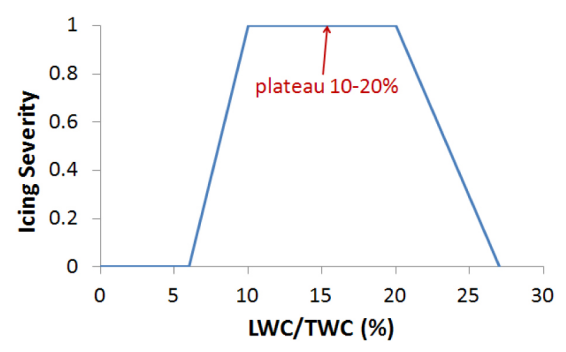

Figure 1: "Plateau" effect: plateau of almost constant icing severity, which drastically decreases at its left and right limits. Reprinted from Currie and Fuleki (2015) with permission from SAE.

ice particles do not contain enough liquid water to stick to the model wall. On the other hand and for large melting ratios (right limit), the amount of liquid water is larger so that the ice particles do not stick and are washed off the surface (Currie et al., 2014). Moreover, erosion effects are strong enough to prevent ice accretion. For intermediate melting ratio, conical ice shapes are observed (Currie et al., 2013, 2014). The influence of the Mach number, total water content (TWC) and pressure $(34.5 \mathrm{kPa}$ and $69 \mathrm{kPa})$ on icing rates have been investigated (Currie et al., 2013, 2014; Currie and Fuleki, 2016). It is shown that the sticking efficiency is almost independant of the Mach number and TWC at normal incidence, near the stagnation point. On the other hand, they are strongly dependant on these parameters at oblique impingement angles (Currie et al., 2014). At the high Mach number of 0.65, ice accretion only occurs with the smallest ice particles with a diameter of $30 \mu \mathrm{m}$ (Currie and Fuleki, 2016). Concerning the influence of total water content, icing severity is significantly increased with TWC at $M=0.25$, but to a lesser extent at $M=0.4$ (Currie et al., 2014). The very large accretions obtained at high TWC are subject to shedding and experimental works have been conducted at NRC on this topic (Currie et al., 2012; Mason et al., 2011). In Currie and Fuleki (2015), an instrument, denoted the Ice Properties Probe (IPP), has been developed to measure the volumetric liquid water content of a mixed phase deposit at $0{ }^{\circ} \mathrm{C}$ to quantify the erosion-related mechanical properties of ice-water mixtures.

The works discussed above are related to accretion tests. To feed the the- 
oretical models, more fundamental studies have been performed, especially about ice crystal impingement. In Hauk et al. (2015), Hauk (2015), Roisman and Tropea (2015), impingements on solid heated and unheated surfaces have been investigated, the surface being covered or not by a liquid layer. The modeling of the ice crystal melting process has been addressed in Hauk et al. (2014, 2016).

Regarding numerical simulation and modeling, previous works dedicated to ice crystal icing have been attempted. In Lozowski et al. (1979), all the impinging ice crystals (or at least a sufficient fraction to freeze all the existing water on the cylinder surface) are supposed to stick when the surface is fully wet. For dry surfaces, all the ice particles bounce off the wall. In Mazzawy (2007), the wall liquid film may splash due to ice crystal impingement. For the so called "zero net mass" model, the amount of liquid water which is splashed out of the wetted surface is equal to the amount of impinging ice crystal. Realistic configurations like partially melted ice particles which stick to the wall and add to the film height are out of the scope of this model. In Wright et al. (2010), modifications have been made to GlennICE for handling ice particles impacts. Improvements concern the solid ice particle trajectory equations (thermal and dynamic), mass loss prediction due to erosion and the extension of the Messinger's mass and energy balance equations (Messinger, 1953) to take into account the presence of ice crystals among the impinging particles. In Habashi and Nilamdeen (2011), the shallow-water icing model (SWIM) has been extended to ice crystal icing. In the rime region, it is assumed that all ice crystals bounce off the surface which is not realistic for partially melted ice particles. Erosion or film splashing are not considered. In Rios Pabon (2012), a multi-layer model is proposed. However, the classical Messinger's formulation is used to compute the runback mass fluxes without taking into account the porosity of the slushy ice deposit.

In Villedieu et al. (2014) the models for trajectory, impingement and accretion have been adapted to the ice crystal icing regime. However, the model for the ice crystal sticking efficiency is based on the presence of a liquid film on the wall which is not necessary for partially melted ice crystals. Erosion phenomena are not taken into account in Villedieu et al. (2014). Ice shedding phenomena, which are typically not predicted by the classical Messinger models but which are common in warm icing conditions, are taken into account in Bennani et al. (2014), Bennani (2014) or Kintea et al. (2016). The HAIC European project has been the opportunity for existing icing tools to be equipped with an ice crystal capability (Iuliano et al., 2015; Ayan et al., 
2015).

The objective of this paper is to derive a comprehensive accretion model for glaciated conditions. The proposed model is based on three main features. Firstly, the classical Messinger model (Messinger, 1953) is extended to account for the presence of ice crystals in the mass and the energy balance equations. In particular, contrary to Messinger (1953), a part of the unfrozen liquid water may remain trapped in the pores of the accreted ice layer instead of running backward, leading to a slushy accretion. Secondly, based on available experimental results (Currie et al., 2014), an empirical expression is derived for the ice crystal sticking efficiency. Lastly, the model accounts for the influence of erosion phenomena which play a very important role in the case of ice crytal icing contrary to the case of supercooled water icing. As the physics is extremely complicated and not completely understood, the proposed correlative models are based on macroscopic experimental observations. However, and this is the point of the models proposed in this paper, they are able to reproduce the tendencies observed experimentally such as the steady-state conical ice shapes, the plateau effect or the sensitivity of the ice shape with the Mach number. Of course, none of these phenomena are hard embedded in the models, but are direct consequences observed by the application of the latter.

In a first part, the models are described. The extended version of the Messinger balance equations for ICI is presented. The model for the ice crystal sticking efficiency as well as the erosion model are presented. In a second part, the numerical overview is proposed where the tools are presented. The experimental database used for the model calibration and validation is presented in a third part. The fourth part is dedicated to computational setup and model calibration. In a fifth part, the models are validated. Finally, conclusions are drawn.

\section{Model description}

Ice crystal icing is a combination of several physical phenomena which need to be modeled. Firstly, ice crystals of different shapes, sizes and velocities impact onto a solid substrate. Some of them may stick to the substrate provided that there is some liquid water. The ice particle deposited mass rate is determined by the sticking efficiency coefficient which has to be modeled. Secondly, the ice layer over the substrate is a porous media. Therefore, a part of the liquid water remains trapped and accumulates in the pores of the 
ice layer. This leads to a new formulation of the runback model for the liquid water. Finally, a part of the accreted ice is ejected by the impacting ice crystals. This phenomenon is described by the erosion model. In this section, the extended Messinger balance for ice particles is presented as well as the new formulation of the runback model. Then, the model for the ice crystal sticking efficiency is presented. Finally, the erosion model is described.

\subsection{The extended Messinger balance}

Several authors (Wright et al., 2010; Villedieu et al., 2014) have already adapted Messinger's mass and energy balance equations to take into account the presence of ice crystals among the impinging particles. The corresponding models are described in Wright et al. (2010) and Villedieu et al. (2014).

\subsubsection{Overview and notations}

Here, to introduce the notations, the general form of the mass balance equation is written:

$$
\left\{\begin{aligned}
\dot{m}_{a c c}^{S}+\dot{m}_{M e s s}^{L} & =\dot{m}_{r b i}+\dot{m}_{d e p}-\dot{m}_{e v s}-\dot{m}_{e r} \\
\dot{m}_{M e s s}^{L} & =\dot{m}_{a c c}^{L}+\dot{m}_{r b o}
\end{aligned}\right.
$$

where $\dot{m}_{r b i}$ is the incoming runback liquid water mass rate, $\dot{m}_{d e p}$ is the particle deposited mass rate, $\dot{m}_{e v s}$ is the evaporated/sublimated mass rate, $\dot{m}_{\text {Mess }}^{L}$ is the net liquid water mass rate (i.e. the mass rate corresponding to the liquid water which does not evaporate, sublimate or freeze during the corresponding time step), $\dot{m}_{a c c}^{S}$ is the accreted ice mass rate and $\dot{m}_{e r}$ is the erosion mass rate. The mass rate $\dot{m}_{\text {Mess }}^{L}$ is splitted between $\dot{m}_{a c c}^{L}$ and $\dot{m}_{r b o}$ which respectively stand for the mass rate of liquid water which remains trapped inside the porous ice layer and the mass rate of running back liquid water. All the terms are summarized in Fig. 2. The particle deposited mass rate $\dot{m}_{d e p}$ derives from the impinging mass rate $\dot{m}_{i m p}$ through the sticking efficiency $\epsilon_{s}$

(Sec. 1.2). The impinging ice crystals are melted so that the liquid $\dot{m}_{i m p}^{L}$ and the solid $\dot{m}_{i m p}^{S}$ impinging mass rates are given by:

$$
\begin{aligned}
& \dot{m}_{i m p}^{L}=\eta_{m} \cdot \dot{m}_{i m p} \\
& \dot{m}_{i m p}^{S}=\left(1-\eta_{m}\right) \cdot \dot{m}_{i m p}
\end{aligned}
$$

where $\eta_{m}$ is the melting ratio of the impinging ice crystals. 


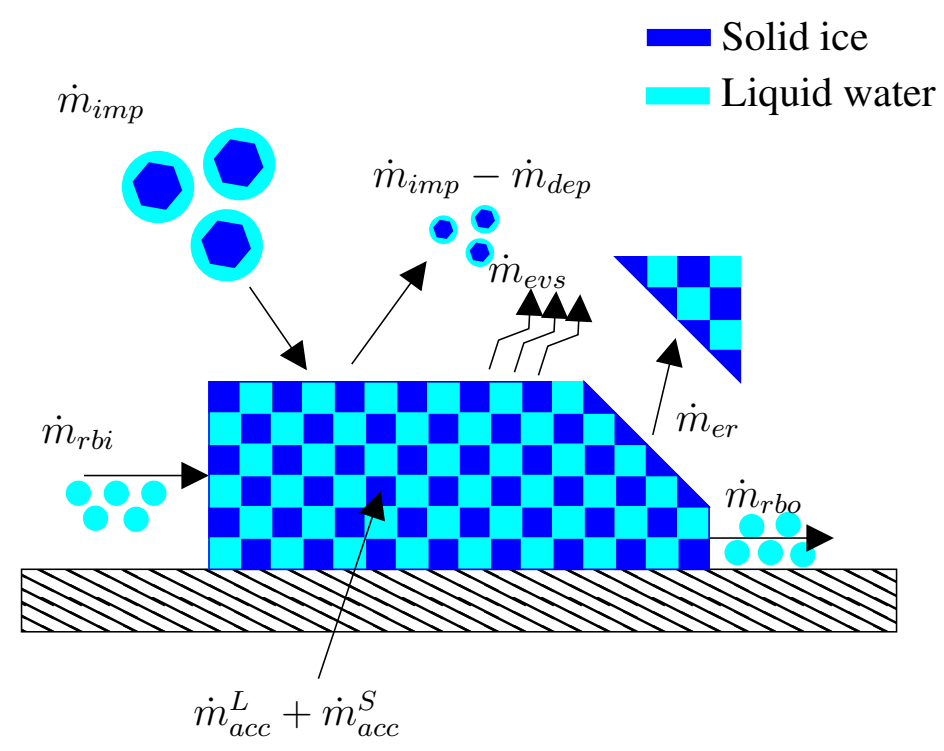

Figure 2: Messinger mass balance. Extension to ice crystal icing. $\dot{m}_{i m p}, \dot{m}_{\text {dep }}, \dot{m}_{\text {evs }}, \dot{m}_{e r}$, $\dot{m}_{r b i}, \dot{m}_{r b o}, \dot{m}_{a c c}^{L}$ and $\dot{m}_{a c c}^{S}$ are respectively the mass rates for impinging ice particles, deposited ice particles, evaporation/sublimation, erosion, incoming runback liquid water, outgoing runback liquid water, liquid water trapped in the pores of the accreted ice layer and solid ice accretion. 


\subsubsection{Runback model}

In the classical Messinger model (Messinger, 1953), the hypothesis that the liquid water may not locally accumulate and is carried downstream by

the air flow $\left(\dot{m}_{a c c}^{L}=0\right.$ and $\left.\dot{m}_{r b o}=\dot{m}_{M e s s}^{L}\right)$ may be justified in the case of supercooled water icing where the frozen droplets form a solid non porous ice layer. But, for ice crystal icing conditions, there are experimental evidences (Currie et al., 2013, 2014) that liquid water may be trapped among the accreted ice particles, leading to the formation of slushy ice deposits. The porosity $\Phi$ of the accreted ice is defined as:

$$
\Phi=\frac{\dot{m}_{a c c}^{L} / \rho_{L}+\dot{m}_{a i r} / \rho_{a}}{\dot{m}_{a c c}^{L} / \rho_{L}+\dot{m}_{a i r} / \rho_{a}+\dot{m}_{a c c}^{S} / \rho_{S}}
$$

where $\dot{m}_{\text {air }}$ is the mass rate of air which remains trapped inside the porous ice layer. $\rho_{L}, \rho_{S}$ and $\rho_{a}$ are respectively the densities of liquid water, solid ice and air. If the porous ice layer is not compacted in some manner, the porosity $\Phi$ is about $40 \%$ since this is a typical value for close-packing spheres. Actually, $\Phi$ is ranged between $26 \%$ for a face-centered cubic or a hexagonal close-packed distribution and $66 \%$ for a diamond cubic structure. $\Phi=0.5$ is chosen here. Therefore, the liquid water may accumulate in the porous ice layer. To account for these phenomena, a model for the runback water has thus to be proposed like in Trontin et al. (2016). The interstices of the porous ice can be filled with both liquid water and air (see Eq. (3)). The volume occupied by the liquid water can thus be written as:

$$
\dot{m}_{a c c}^{L} / \rho_{L}=H\left(\eta_{m}\right) \cdot\left(\dot{m}_{a c c}^{L} / \rho_{L}+\dot{m}_{a i r} / \rho_{a}\right)
$$

where $H\left(\eta_{m}\right)$ is the ratio of the liquid water in the interstices of the porous ice. $H$ is a function of $\eta_{m}$ ranging between 0 and 1 . It is chosen so that in the case of supercooled water icing $\left(\eta_{m}=1\right)$, the hypothesis of the classical Messinger model (Messinger, 1953) is satisfied $\left(\dot{m}_{a c c}^{L}=0\right)$. The following expression is then proposed for the function $H$ :

$$
H\left(\eta_{m}\right)=1-\eta_{m}^{2}
$$

so that the classical supercooled water icing actually appears like a degenerate configuration of the model. Combining Eqs. (4) and (5), $\dot{m}_{a c c}^{L}$ can be written as:

$$
\dot{m}_{a c c}^{L} / \rho_{L}=H\left(\eta_{m}\right) \cdot G(\Phi) \cdot \dot{m}_{a c c}^{S} / \rho_{S}
$$


where

$$
G(\Phi)=\frac{\Phi}{1-\Phi}
$$

$G$ is an increasing function of $\Phi$, which means that the more porous the ice, the more liquid water can accumulate. For the assumed value of $\Phi=0.5$ (see hereinabove), $G=1$. In the absence of experimental data dedicated to the modelling of $\Phi$, this value is chosen for the function $G$ in this study. Given that $\rho_{L} \approx \rho_{S}$, and according to Eq. (6), the runback model, i.e. the split of the water mass flow rate $\dot{m}_{\text {Mess }}^{L}$ between $\dot{m}_{a c c}^{L}$ and $\dot{m}_{r b o}$, is given by:

$$
\left\{\begin{array}{l}
\dot{m}_{a c c}^{L}=\min [H\left(\eta_{m}\right) \cdot G(\Phi) \cdot \dot{m}_{a c c}^{S} ; \underbrace{\dot{m}_{M e s s}^{L}}_{(1)}] \\
\dot{m}_{r b o}=\dot{m}_{\text {Mess }}^{L}-\dot{m}_{a c c}^{L}
\end{array}\right.
$$

Term (1) defines the upper limit value for $\dot{m}_{a c c}^{L}$ which cannot be larger that the amount of available liquid water $\dot{m}_{\text {Mess }}^{L}$ computed from the Messinger's mass and energy balance equations.

\subsection{Model for the ice crystal sticking efficiency}

The particle deposited mass rate $\dot{m}_{\text {dep }}$ is computed from the impinging mass rate $\dot{m}_{i m p}$ thanks to:

$$
\dot{m}_{d e p}=\epsilon_{s} \cdot \dot{m}_{i m p}
$$

where $\epsilon_{s}$ denotes the sticking efficiency. $\epsilon_{s}$ is computed according to the following empirical model:

$$
\epsilon_{s}=F\left(\eta_{m}\right)
$$

where the function $F$ has to meet the following conditions:

1. In the absence of liquid water, pure ice crystals $\left(\eta_{m}=0\right)$ bounce off the wall $\left(\epsilon_{s}=0\right)$. Therefore, $F(0)=0$.

2. For the supercooled water icing regime $\left(\eta_{m}=1\right)$, all the droplets stick to the wall $\left(\epsilon_{s}=1\right)$. Therefore, $F(1)=1$.

3. In the experiments from Currie et al. (2014), it is shown that for a crowned cylinder, the sticking efficiency near the stagnation point is a function of the particle melting ratio $\eta_{m}$. More specifically, for low $\eta_{m}, \epsilon_{s}$ is a linear function of $\eta_{m}$ (see Appendix A.2 dedicated to the calibration of the model for $\left.\epsilon_{s}\right)$. Therefore, $F\left(\eta_{m}\right) \approx K^{\#} \cdot \eta_{m}$ at low $\eta_{m}$ (with $K^{\#}$ an adjustable parameter to be calibrated). 
4. The function $F$ is expected to be a smooth increasing function which tends to 1 when $\eta_{m} \rightarrow 1$.

Given all these conditions, the following polynomial expression is chosen for $F$ :

$$
F\left(\eta_{m}\right)=\left(K^{\#}-2\right) \eta_{m}^{3}+\left(3-2 K^{\#}\right) \eta_{m}^{2}+K^{\#} \eta_{m}
$$

\subsection{Erosion model}

$\dot{m}_{M e s s}^{L}$ and $\dot{m}_{a c c}^{S}$ are updated to take into account the erosion effects. The erosion mass rate $\dot{m}_{e r}$ is defined as:

$$
\dot{m}_{e r}=\min [\underbrace{\dot{m}_{a c c}^{S}+\dot{m}_{M e s s}^{L}}_{(*)}, \min \left(1, \epsilon_{e r}\right) \cdot \dot{m}_{i m p}]
$$

where $\dot{m}_{i m p}$ is the ice crystal impinging mass rate. The term $(*)$ in Eq. (12) means that the upper limit value for $\dot{m}_{e r}$ is $\dot{m}_{a c c}^{S}+\dot{m}_{\text {Mess }}^{L}$ which represents the total amount of solid $\left(\dot{m}_{a c c}^{S}\right)$ and liquid $\left(\dot{m}_{\text {Mess }}^{L}\right)$ water available on the wall. The following empirical model for the erosion efficiency $\epsilon_{e r}$ is proposed:

$$
\epsilon_{e r}=E \underbrace{\left(\frac{V_{i m p}^{t}}{V_{0}}\right)^{2}}_{(1)} \cdot \underbrace{\frac{y_{l 0}}{y_{l 0}-\min \left(y_{l}, y_{l 0}\right)}}_{(2)} \cdot \underbrace{\left[1+\left(l_{0} \kappa\right)^{2}\right]}_{(3)}
$$

where $V_{i m p}^{t}$ denotes the mean tangential velocity of the impinging ice crystals and $y_{l}$ is the wall liquid mass fraction defined by:

$$
y_{l}=\frac{\dot{m}_{a c c}^{L}}{\dot{m}_{a c c}^{L}+\dot{m}_{a c c}^{S}}
$$

$y_{l}=0$ stands for a pure ice layer with no water trapped inside and which sticks firmly to the wall. $y_{l}=1$ is an asymptotic value with only liquid water. $\kappa$ is the local curvature of the ice layer surface. $E, V_{0}, y_{l 0}$ and $l_{0}$ are empirical constants which have to be estimated thanks to experimental results (see Appendix A).

The term (1) in Eq. (13) is justified from experimental observations where conical ice shapes in Currie et al. $(2013,2014)$ and the erosion effects near the impingement limits in Currie et al. (2012) indicate that the erosion rate seems to mainly depends on the tangential component of the velocity of the 
impinging ice crystals. Term (2) defines a critical value for $y_{l}$. For large wall liquid mass fractions $\left(y_{l} \gtrsim y_{l 0}\right)$, the slushy ice deposit at the wall contains too much liquid water and cannot stick to the wall due to erosion and continuous shedding phenomena. Term (3) accounts for the smoothing effect of erosion. The higher the local curvature, the higher the erosion rate.

\section{Numerical overview}

The numerical tool used to develop and calibrate the aforementioned models is the ONERA 2D icing tool IGLOO2D (Trontin et al., 2017). An overview of the tool is proposed in Fig. 3. It is mainly composed of four
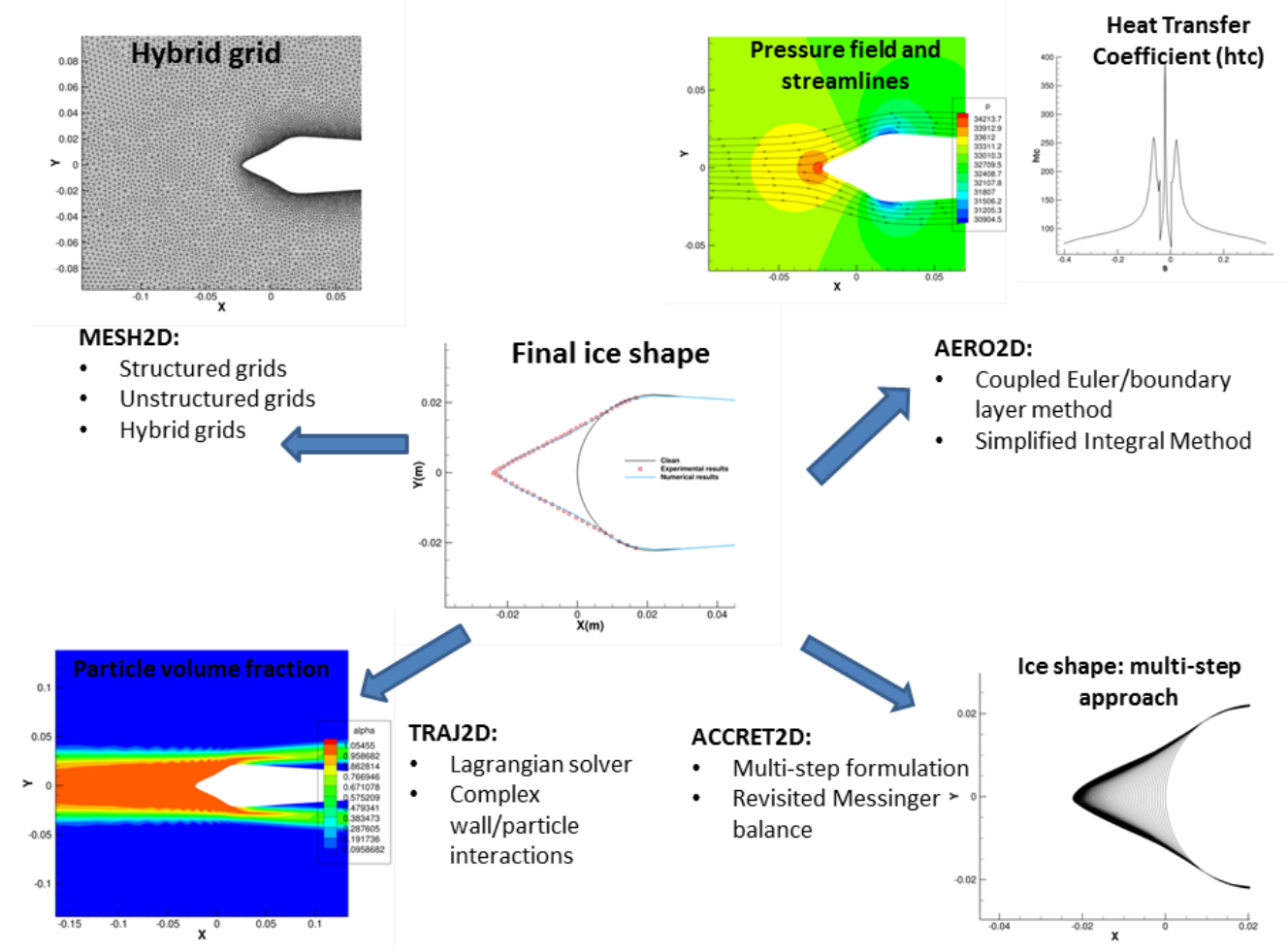

Figure 3: IGLOO2D overview. The ONERA 2D icing tool is mainly composed of four components: the MESH2D grid generation tool, the AERO2D aerodynamic flow solver, the TRAJ2D trajectory solver and the ACCRET2D ice accretion solver.

components: 
- The MESH2D grid generation tool is dedicated to the building of both structured, unstructured, and hybrid grids.

- The AERO2D aerodynamic flow solver computes the aerodynamic field (air pressure, velocity and temperature, recovery temperature, heat transfer coefficient or local steam mass fraction). It can be obtained by the resolution of the Navier-Stokes equations or by the coupling between the resolution of the inviscid equations (potential flow theory or Euler equations) for the external flow field and the resolution of the boundary layer equations (Prandtl equations).

- The TRAJ2D trajectory solver is dedicated to the computation of the particulate flowfield (crystals and droplets). Two solvers respectively based on a Lagrangian (TRAJL2D) and an Eulerian (TRAJE2D) description are available. The model dedicated to the ice crystal sticking efficiency $\epsilon_{s}$ (Eq. (10)) is developed in TRAJ2D.

- The ACCRET2D ice accretion solver computes ice accretion from the outputs provided by the aerodynamic and the dispersed two-phase flow solvers. The revisited Messinger model for ice crystal icing as well as the models dedicated to erosion and modified runback are implemented in ACCRET2D.

From the computational point of view, the total ice accretion time $\Delta t$ is divided into $N$ sub-steps. The final ice deposit thickness $e_{i c e}$ computed during $\Delta t$ is given by:

$$
e_{i c e}=\sum_{i=1}^{N} e_{i c e}^{i}
$$

where $e_{i c e}^{i}$ is the accreted ice thickness computed during the time interval $\left[t^{i} ; t^{i+1}\right], t^{i}$ being defined by:

$$
t^{i}=\frac{i-1}{N} \Delta t
$$

At the beginning $t^{i}$ of each new step, the aerodynamic flow field at the outer edge of the boundary layer (outer velocity, pressure, temperature, ... ), the characteristics of the boundary layer (recovery temperature and heat transfer coefficient) and the properties of the impinging particles (sticking efficiency, 
temperature, ...) are updated. Then the ice growth during $\left[t^{i} ; t^{i+1}\right]$ is computed by the ACCRET2D solver and the ice deposit shape is updated for the next time step. The directions used for the ice growth during $\left[t^{i} ; t^{i+1}\right]$ are the updated local normal vectors to the transient iced profile. This procedure known as the multi-timestep method (called hereafter the multistep method) is detailed in Trontin et al. (2017).

\section{Presentation of the experimental database used for model cali- bration and validation}

In 2013 and 2014, NRC performed several ice crystal accretion experiments in their small altitude wind tunnel (Currie et al., 2013, 2014). In these experiments, ice crystals are produced by a grinder and are entrained in a jet of sub-freezing air blowing into the inlet of the icing tunnel $\left(\approx-15^{\circ} \mathrm{C}\right)$. Before entering the tunnel, cold airflow mixes with the surrounding warm air from the altitude cell to produce a mixed-out temperature $T_{0}$ inside the tunnel. This mixing may promote ice particle melting when the wet bulb temperature of the mixed airflow is greater than $0{ }^{\circ} \mathrm{C}$. The melting ratio $\eta_{m}$ of the ice crystals was adjustable by adjusting the wet bulb temperature $T_{w b}$.

The test article is a nominally 2D planar geometry with a crowned cylindrical nose (Fig. 4). The test-cases from Currie et al. (2014) used for the

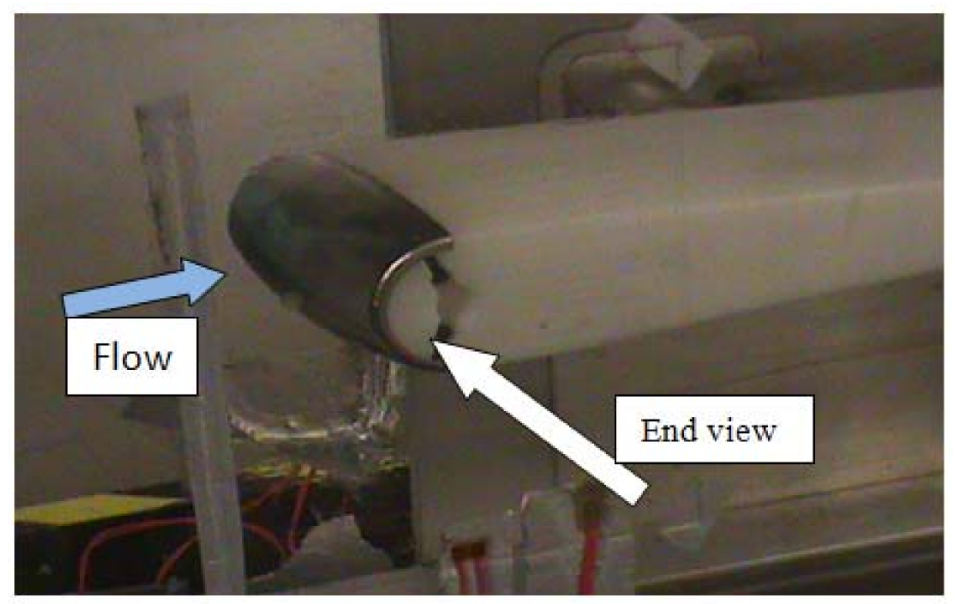

Figure 4: Nominally 2D planar geometry with crowned cylindrical nose. Reprinted from Currie et al. (2014) with permission from AIAA. 


\begin{tabular}{|c|c|c|c|}
\hline Run name & $M_{0}$ & $T_{w b 0, w e t}$ & $\eta_{m}$ \\
\hline run\#17 & 0.25 & $0.2{ }^{\circ} \mathrm{C}$ & $6 \%$ \\
run\#77 & 0.25 & $1.6{ }^{\circ} \mathrm{C}$ & $11.2 \%$ \\
run\#67 & 0.25 & $2.6{ }^{\circ} \mathrm{C}$ & $16.6 \%$ \\
run\#92 & 0.25 & $5.0{ }^{\circ} \mathrm{C}$ & $26.4 \%$ \\
run\#101 & 0.25 & $6.0{ }^{\circ} \mathrm{C}$ & $40 \%$ \\
\hline
\end{tabular}

Table 1: Test case description (from Currie et al. (2014)). $P_{0}=34.5 \mathrm{kPa}, T_{0}=15{ }^{\circ} \mathrm{C}$, $I W C=6$ g.m $\mathrm{m}^{-3}$. Run\#67 is used to calibrate the empirical models proposed in this paper. Validation is carried out with runs \#17, \#77, \#92 and \#101.

model calibration and validation are detailed in Tab. 1. All the considered tests correspond to a Mach number $M_{0}$ of 0.25 and a total pressure $P_{0}$ of $34.5 \mathrm{kPa}(5 \mathrm{psia})$. The total air temperature $T_{0}$ is nominally $+15{ }^{\circ} \mathrm{C}$ for all the tests. The corresponding velocity is $84.5 \mathrm{~m} . \mathrm{s}^{-1}$. Therefore the reference velocity $V_{0}$ in Eq. (13) is chosen so that:

$$
V_{0}=84.5 \mathrm{~m} . \mathrm{s}^{-1}
$$

The wet bulb temperature was increased from $0{ }^{\circ} \mathrm{C}$ to $+6{ }^{\circ} \mathrm{C}$ at the given pressure $P_{0}$ while holding the injected ice flowrate fixed, thereby producing the range of desired melt ratios at effectively constant injected IWC (Currie et al., 2014). The "wet" wet bulb temperature $T_{w b 0, w e t}$ in Tab. 1 is based on the total temperature and pressure and is computed after the ice crystals have been injected (ice spray on). The wet bulb temperatures for runs \#17, \#77, \#67 and \#92 are not provided in Currie et al. (2014). In order to set these temperatures, data from Currie et al. (2013) are used. Indeed, the aerodynamics and icing conditions are similar between run\#17 (resp. run\#77, run\#67 and run\#92) from Currie et al. (2014) and run\#1286 (resp. run\#1117, run\#1139 and run\#1123) from Currie et al. (2013). Therefore, the wet bulb temperature in run\#17 (resp. run\#77, run\#67 and run\#92) is taken to be the same as in run\#1286 (resp. run\#1117, run\#1139 and run\#1123) from Currie et al. (2013). These values are given in Tab. 1. The only difference is the test article: an hemispherical nose in Currie et al. (2013) and a crowned cylinder (Currie et al., 2014) in our study, which has no influence on the farfield wet bulb temperature. Wet bulb temperature for the run\#101 (Tab. 1) has been set to the maximum allowed value $+6{ }^{\circ} \mathrm{C}$. It is mentioned in Currie et al. (2014) that the hot-wires from the SEA probe 
used to measure LWC under mixed-phase conditions provide good results for supercooled liquid droplets. However, they have not been calibrated to measure LWC in mixed-phase ice-water flows where the water is produced by the melting of ice crystals. The probe is supposed to underestimate LWC because it probably does not completely capture liquid water coating the melting ice crystals (Currie et al., 2014). The measurements at high levels of impinging (liquid) water mass flux may not provide accurate values since the response of the hot wires decreases at those conditions (Currie et al., 2014). That is why in Tab. 1 , for the highest melting ratio, $\eta_{m}=40 \%$ has been chosen instead of $\eta_{m}=31.4 \%$. Note that both $\eta_{m}=31.4 \%$ and $\eta_{m}=40 \%$ correspond to the right end of the plateau (see Fig. A.14 from the calibration section in Appendix A.2). Therefore, the uncertainties of the measurement of liquid water at high melting ratio by the probe $\left(\eta_{m}=31.4 \%\right.$ or $\eta_{m}=40 \%$ ) will have no consequences on the qualitative conclusions, namely the capability of the model to predict the decrease of ice accretion at high melting ratios.

Regarding the particle size distribution (PSD), the 7-bins distribution proposed in Currie et al. (2014) is used leading to a mass median diameter $\left(D_{50}\right)$ of $45 \mu \mathrm{m}$ and a mass mean diameter $D_{43}$ of $52.7 \mu \mathrm{m}$. Since the publication of the experimental results in Currie et al. (2014), the procedure used to calculate the PSD from shadowgraphs (Knezevici et al., 2013) has been modified slightly, resulting in small changes in the PSD (Currie et al., 2015). The revised $D_{50}$ and $D_{43}$ are $57 \mu \mathrm{m}$ and $69.7 \mu \mathrm{m}$ respectively. The 9-bin representation of the revised PSD is detailed in Currie et al. (2015). It is shown in Appendix A.4 that using either $D_{43}=52.7 \mu \mathrm{m}$ or $D_{43}=69.7 \mu \mathrm{m}$ as an input for the diameter of the injected particles leads to similar computed ice shapes.

Figure 5 shows experimental views of accretion shapes obtained by Currie et al. (2014) for the cases presented in Tab. 1. Except for run\#67 at $\eta_{m}=$ $16.6 \%$, all the runs shown in Fig. 5 reached steady-state (Currie et al., 2014).

\section{Computational setup and model calibration}

Run\#67 (Tab. 1) is the best documented case from the database presented in Sec. 3 since the ice shapes are provided at different times as well as the time evolution of the ice thickness at the tip. For this reason, the operating conditions for run\#67 were selected to calibrate the main param- 


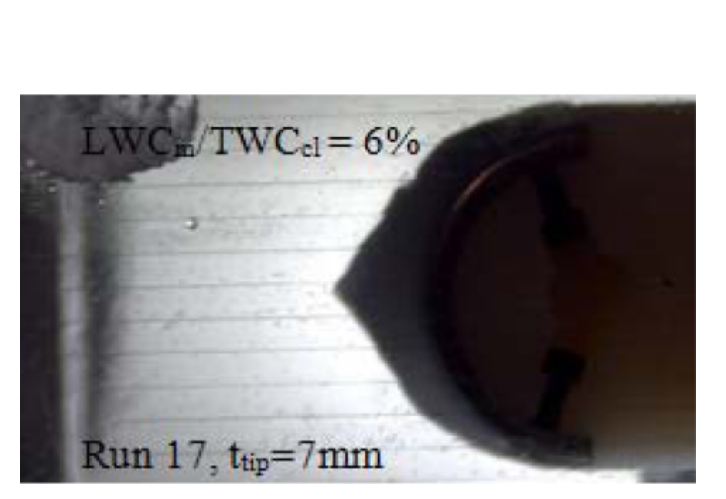

(a)

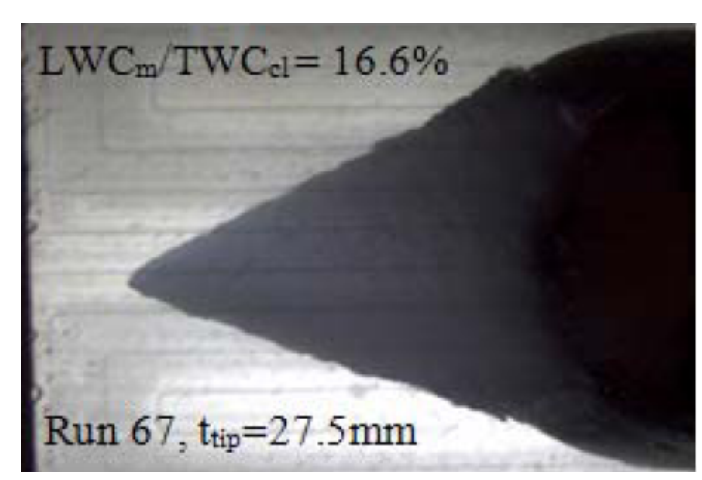

(c)

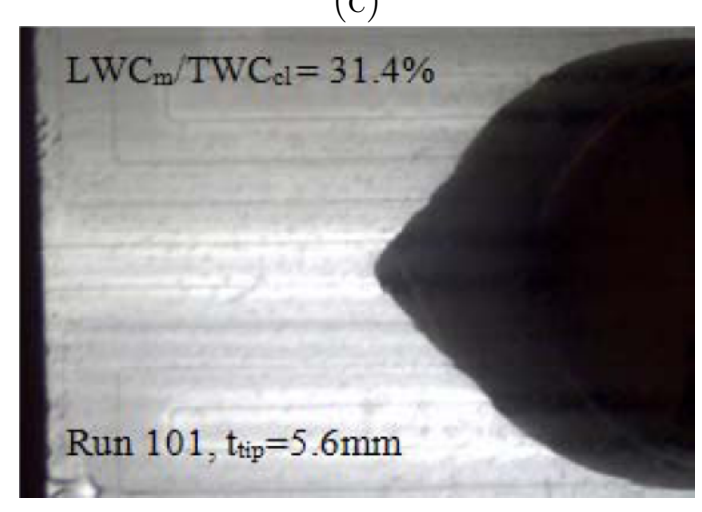

(e)

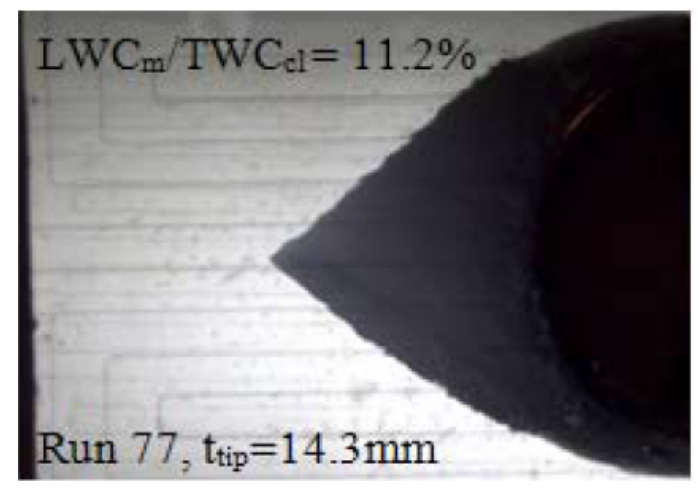

(b)

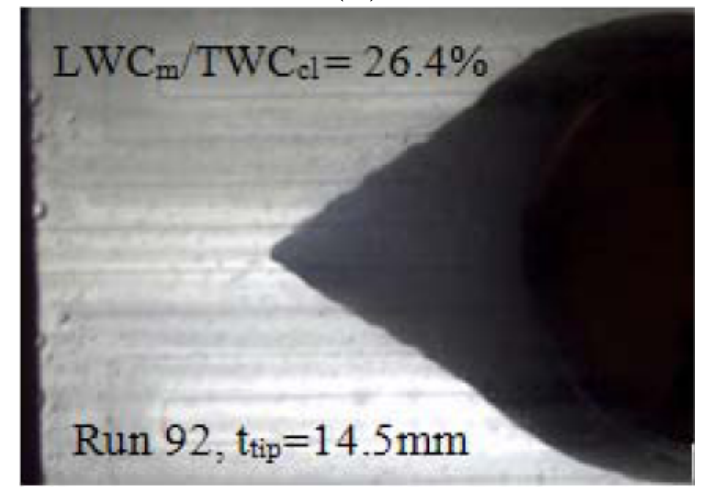

(d) 
eters of the models described in Sec. 1. The calibration process as well as the computational process used in this study are detailed in Appendix A.

\section{Model validation}

This section shows how the models presented in Sec. 1 are capable of reproducing the experimental trends observed in Currie et al. (2014). First of all, numerical simulations allow the calculation of stationary ice thicknesses whose conical shape is in agreement with that obtained experimentally. Secondly, the existence of optimal icing conditions as a function of the melting ratio of ice crystals (the so-called "plateau" effect) is well represented. Thirdly, the fraction of liquid water in the slushy ice layer predicted by the runback model is consistent with the one measured experimentally. Finally, the effects of the Mach number on the ice shape is well taken into account by the model.

Runs \#17, \#77, \#92 and \#101 from the database of Currie et al. (2014) (see Tab. 1) have been used to validate the models. Although they derive from the same experimental database as run \#67 used for calibration, they are sufficiently different from this latter (notably regarding the melting ratio) to be used as validation cases for the models. Run \#67 alone is not enough to validate the correlations between the experimental observations and the numerical results. For instance, regarding the plateau effect (Fig. 1), that is to say the influence of the ice crystal melting ratio $\left(\eta_{m}\right)$ on the final ice shape, the model cannot be validated only with run \#67 which corresponds to a single melting ratio. The use of the whole database (from run \#17 to run \#101) with the whole range of melting ratios allows to validate the model for the plateau effect. In the meantime, a validation can be found in Baumert et al. (2018) on the basis of the experiments conducted at TU Braunschweig under mixed-phase conditions.

\subsection{Stationary conical ice shapes}

Figure 6 shows the time evolution of the computed ice shapes for runs \#17, \#77, \#92 and \#101. In Currie et al. (2014), except for run\#67, all the runs reached steady-state. This trend is found in numerical simulations where, except near the stagnation point, a stationary conical ice shape is obtained. Near the stagnation point, a thin dendritic ice shape grows. This has no physical justification and it is located in an area where the component of the impact velocity is mainly normal to the wall and where the influence of 

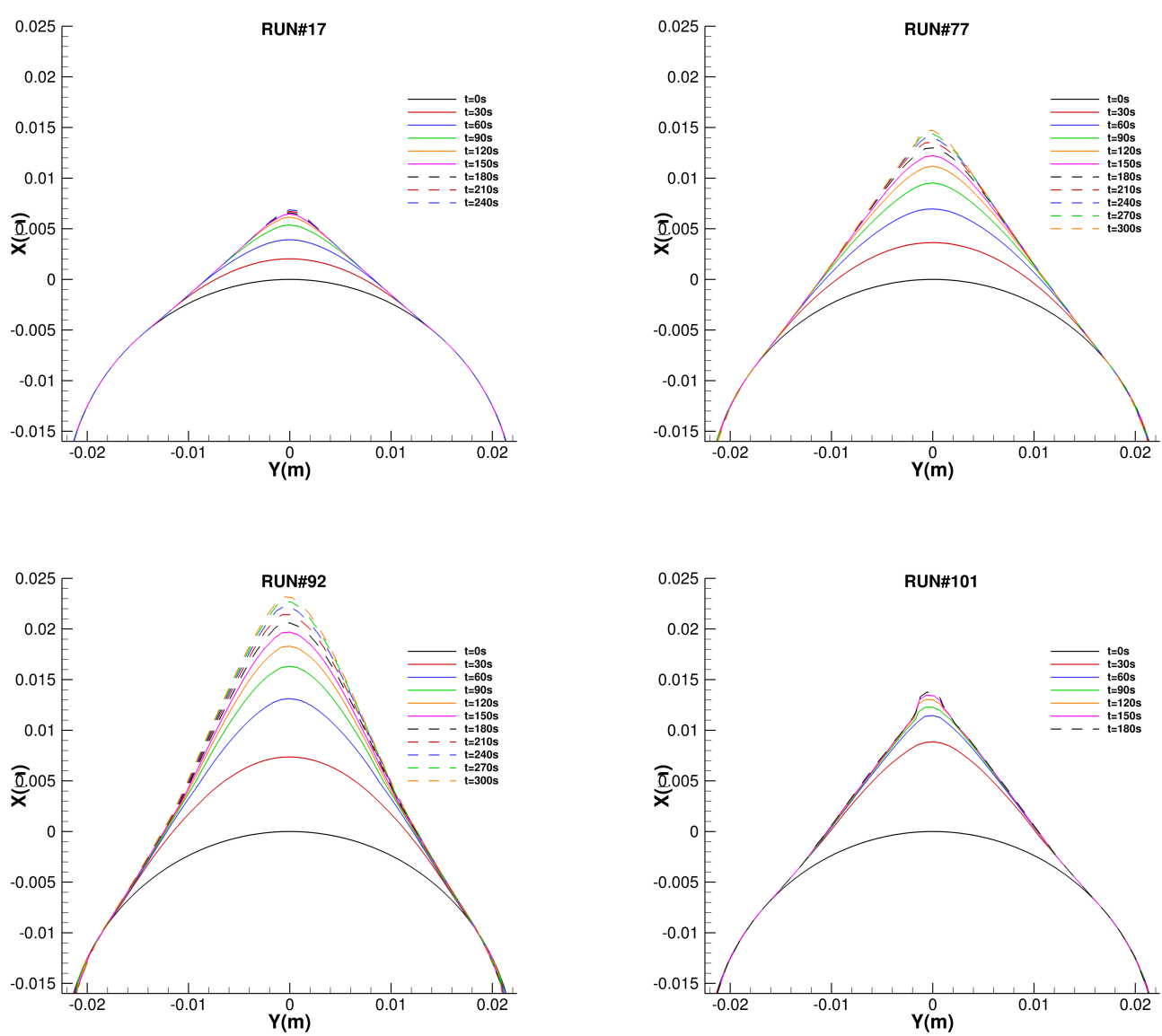

Figure 6: Model validation (runs \#17, \#77, \#92 and \#101). A stationary conical ice shape is obtained. 
the erosion model is the lowest (Eq. (13)). The formation of these dentrites is one of the weaknesses of the proposed model, although attenuated by the term (3) of the erosion model (Eq. (13)).

\subsection{Plateau effect}

It has been shown in Struk et al. (2011), Currie et al. (2012, 2014) and Knezevici et al. $(2012,2013)$ that significant ice accretion has been observed for melting ratios $\eta_{m}$ ranging from 5 to 35 percent, with a "plateau" of almost constant icing severity, which drastically decreases at its left and right limits (see Fig. 1). Figure 7 shows the computed ice shapes obtained for runs \#17, \#67, \#77, \#92 and \#101 (light blue). A comparison with the experimental steady state ice thicknesses at the tip (red dashed line) is proposed. For run\#67, the experimental ice shape at $t=382 \mathrm{~s}$ is provided. The present

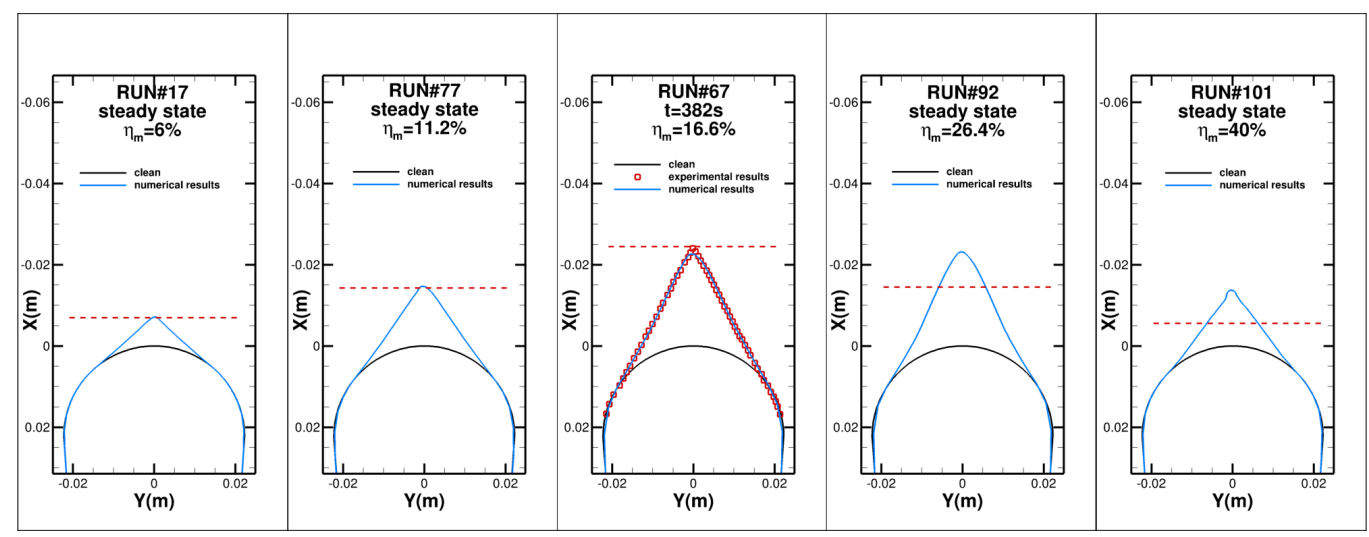

Figure 7: Model validation: Plateau effect. Computed ice shapes for run\#17, \#67, \#77, \#92 and \#101. Comparison between the experimental (red dashed line) and the computed (blue curve) steady state ice thicknesses at the tip.

model is able to capture the so-called "plateau" effect at least for the left part of the plateau (low melting ratios). This is less the case for high melting ratios where the decrease of ice accretion is not as drastic as expected. There are two possible explanations for these discrepancies. Firstly, for high melting ratios, the adhesion of the slushy ice layer to the wall is reduced due to the high liquid water content of the ice. Thus, shedding phenomena may appear due to the aerodynamic forces like for run\#67 where ice starts to be shed before reaching steady-state. The version of the model presented in this 
paper does not take into account the shedding process. This process will be incorporated in future versions of the model. Secondly, for high melting ratios, ice particles do not stick and are washed off the surface since too much water is present (Currie et al., 2014). The model for sticking efficiency (Eqs. (10) and (11)) has been calibrated for small melting ratios (see Sec. 1.2) and is an increasing function of $\eta_{m}$ (Eq. (11)). Therefore, future works should be dedicated to extend the sticking efficiency model to high melting ratios.

\subsection{Consistent runback model}

Figure 8 shows the wall liquid mass fractions $y_{l}$ for different $\eta_{m}$. In the ice

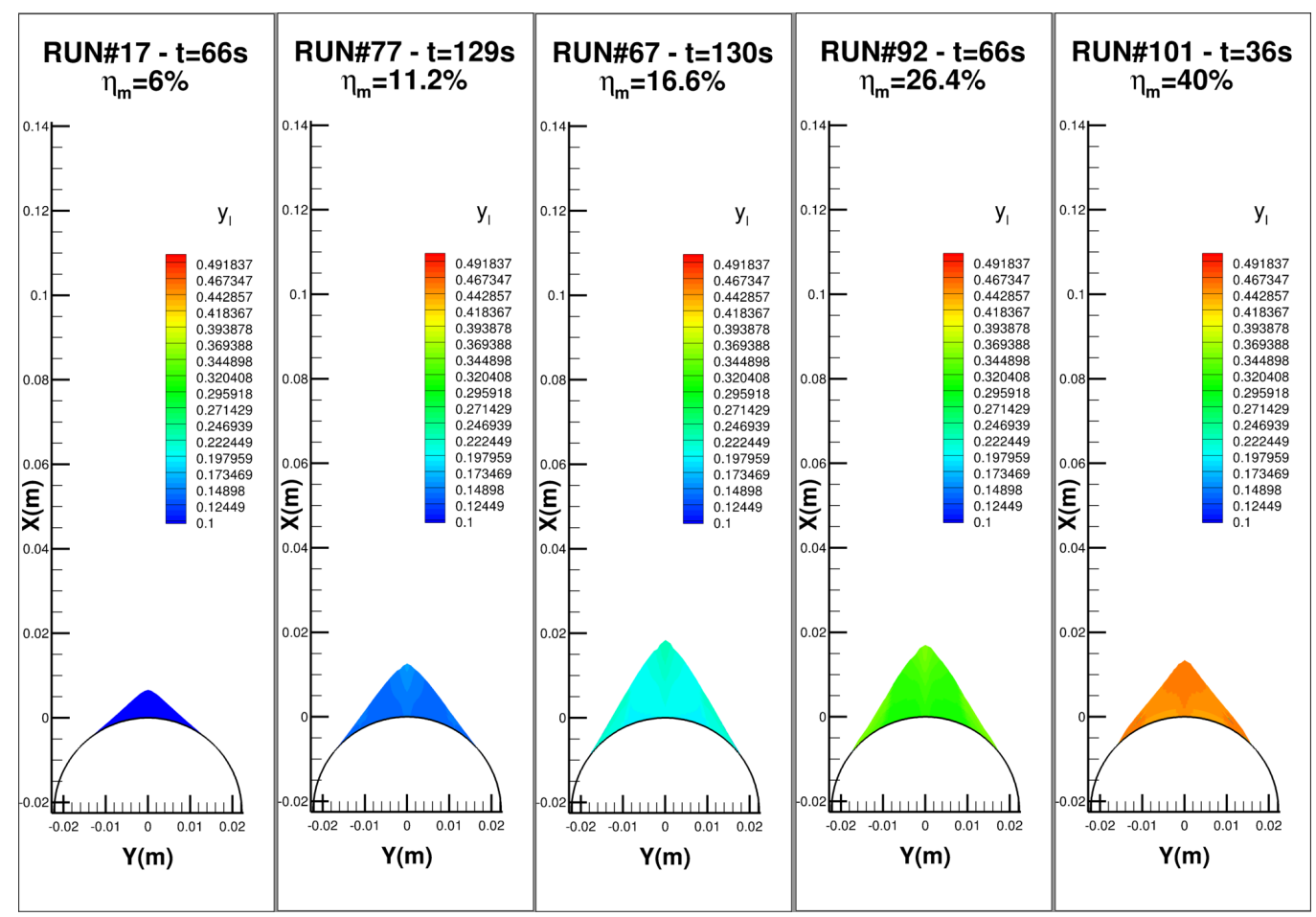

Figure 8: Wall liquid mass fraction $y_{l}$ for different melting ratio $\eta_{m} . y_{l}$ represents the amount of liquid water trapped in the pores of the accreted ice layer instead of running backward, leading to a slushy accretion. $y_{l}=0$ stands for a pure ice layer with no water trapped inside and which sticks firmly to the wall. $y_{l}=1$ is an asymptotic value with only liquid water.

shape as a whole, $y_{l}$ increases with the melting rate $\eta_{m}$, which is consistent 
with an increase in the erosion rate with the melting ratio. Figure 9 compares the wall liquid mass fraction $y_{l}$ obtained by the model with that measured experimentally by the IPP $\left(y_{l}^{e x p}\right)$ for the cylindrical test article at $M_{0}=0.25$, $P_{0}=34.5 \mathrm{kPa}$ and $4<I W C<12 \mathrm{~g} \cdot \mathrm{m}^{-3}$ (see Fig. 14 from Currie and Fuleki (2015)). The values for $y_{l}$ with the corresponding error bars have been derived

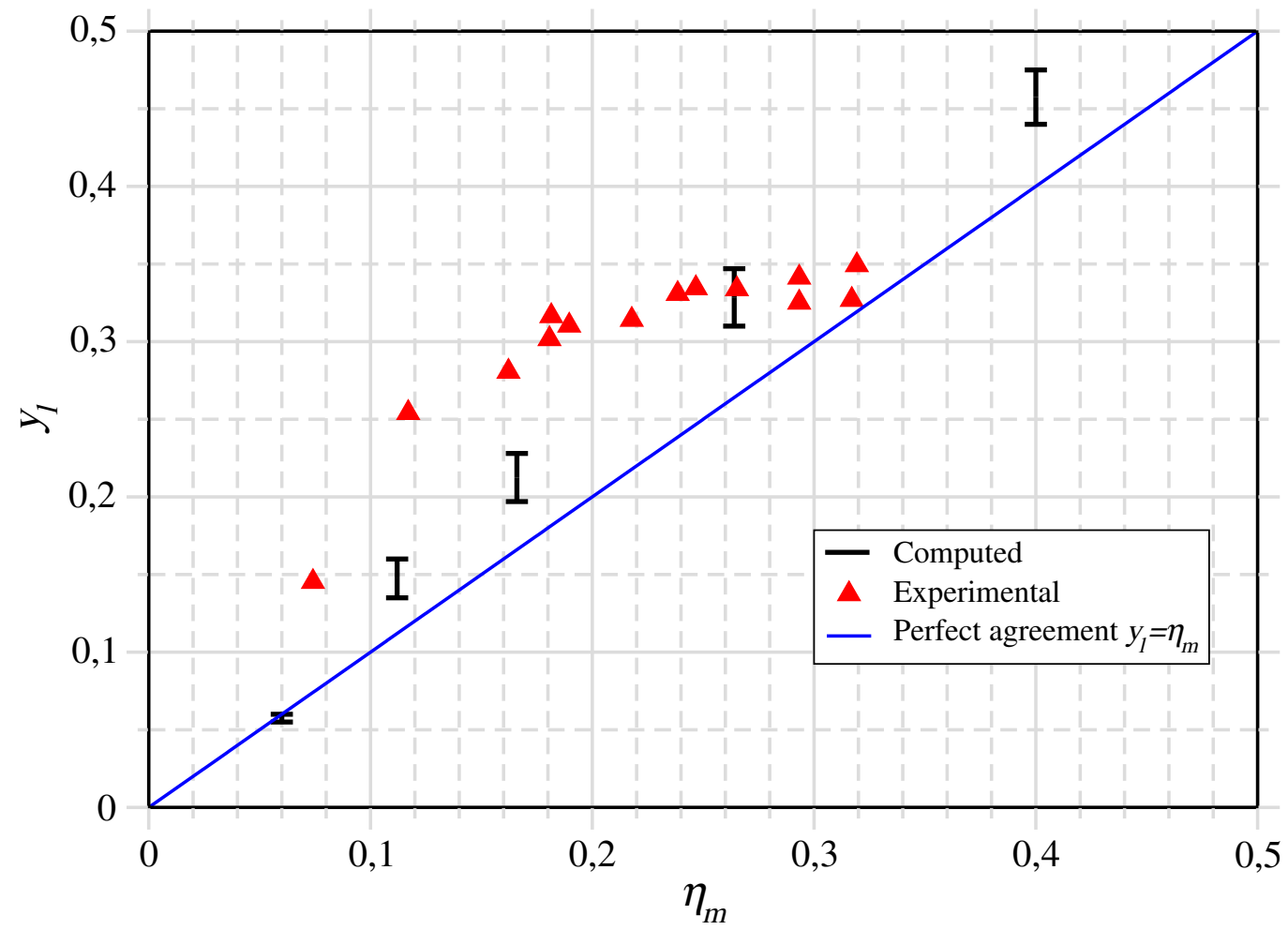

Figure 9: Model validation. Comparison between the computed $y_{l}$ and the experimental $y_{l}^{\text {exp }}$ measured by the IPP for the cylindrical test article at $M_{0}=0.25, P_{0}=34.5 \mathrm{kPa}$ and $4<I W C<12$ g.m ${ }^{-3}$ (Fig. 14 from Currie and Fuleki (2015)). The straight line $y_{l}=\eta_{m}$ is also drawn showing that the wall liquid mass fraction $y_{l}$ is larger than the ice particle melting ratio $\eta_{m}$. This trend is properly addressed by the model.

from Fig. 8. The straight line $y_{l}=\eta_{m}$ is also represented (blue line). For all melting ratios, the wall liquid mass fraction is greater than the melting ratio of the impinging ice crystals $\left(y_{l}>\eta_{m}\right)$. This tendency, which is well taken into account by the model, means that there is more liquid water in the slushy ice layer at the wall than in the partially melted ice crystals impinging the body. This additional water comes from the melting of the ice crystals 


\begin{tabular}{|c|c|c|c|}
\hline Run name & $M_{0}$ & $T_{w b 0, w e t}$ & $\eta_{m}$ \\
\hline run\#233 & 0.4 & $0.9^{\circ} \mathrm{C}$ & $8.6 \%$ \\
run\#238 & 0.4 & $2.1^{\circ} \mathrm{C}$ & $14 \%$ \\
run\#243 & 0.4 & $2.7^{\circ} \mathrm{C}$ & $17.2 \%$ \\
run\#246 & 0.4 & $3.8^{\circ} \mathrm{C}$ & $21.4 \%$ \\
\hline
\end{tabular}

Table 2: Mach number effect. Test case description (from Currie et al. (2014)). $P_{0}=$ $34.5 \mathrm{kPa}, T_{0}=15^{\circ} \mathrm{C}, I W C=6 \mathrm{~g} \cdot \mathrm{m}^{-3}$.

when they stick to the wall. This water supply, resulting from Messinger's thermodynamic balance equations, is well reproduced by the model. On the other hand, the model is not able to predict the plateau for $y_{l}$ obtained experimentally for $\eta_{m}>0.2$. Instead, the model predicts a linear increase of $y_{l}$ with the melting ratio of the ice crystals. This weakness in the model is due on the one hand to a poor estimation of the porosity of the slushy ice layer at the wall (see Eq. (3)). On the other hand, further studies are needed to determine the dependence of $\dot{m}_{a c c}^{L}$ on the melting ratio $\eta_{m}$ (see function $H$, Eq. (5)).

\subsection{Mach number influence}

The figure 10 shows the effect of the Mach number on the ice shape. The test cases derived from Currie et al. (2014) are summarized in Tab. 2. In the absence of further information on experimental data, it has been assumed that the correspondence between the "wet" wet bulb temperature $T_{w b 0, w e t}$ and the ice crystal melting ratio $\eta_{m}$ is the same for both Mach numbers 0.25 and 0.4. This means that for fixed $T_{0}, P_{0}$ and $T_{w b 0, w e t}$, moving from $M_{0}=0.25$ to $M_{0}=0.4$ results in increasing the relative humidity of the air in the numerical simulations.

The ice thickness at the stagnation point is well predicted by the model when the Mach number is raised from 0.25 to 0.4 . This validates the term $\left(\frac{V_{i m p}^{t}}{V_{0}}\right)^{2}$ of the erosion model (Eq. (12)). For the higher melting ratios, the model is not capable of reproducing the trend observed by the experimental results, i.e. a total absence of ice accretion. Like for $M_{0}=0.25$ at high melting ratios, the shedding phenomenon as well as the decrease in the sticking efficiency $\epsilon_{s}$ are not taken into account in the models proposed here. 

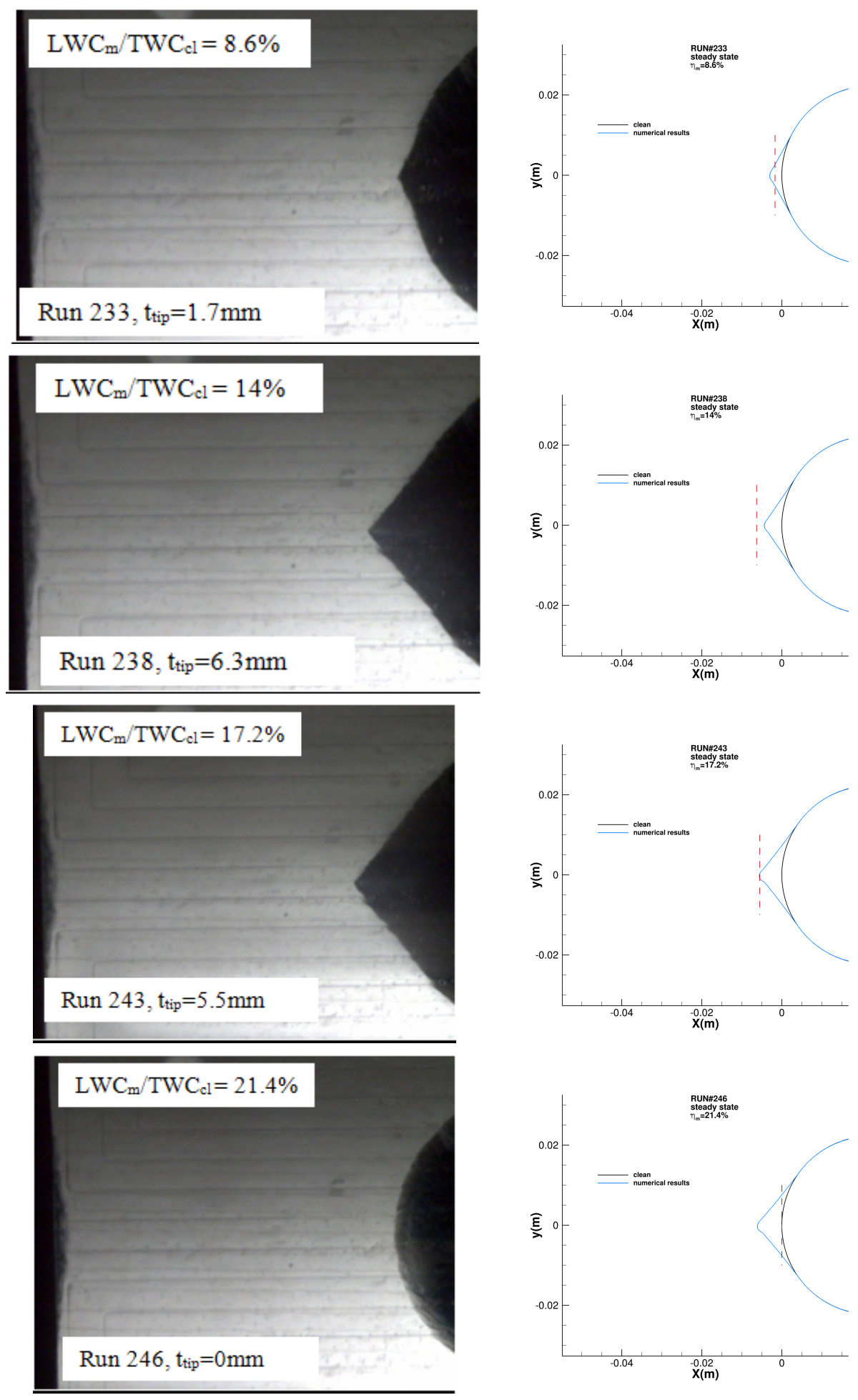

24

Figure 10: Model validation: Mach number effect (runs \#233, \#238, \#243 and \#246, see Tab. 2). $M_{0}=0.4, P_{0}=34.5 \mathrm{kPa}$ and $T_{0}=15^{\circ} \mathrm{C}$. Comparison between the experimental (red dashed line) and the computed (blue curve) steady state ice thicknesses at the tip. 


\section{Conclusions}

In this article, an extension of the Messinger model for the ice crystal icing regime has been presented. Glaciated conditions have been studied. Due to the great complexity and very incomplete knowledge of the physical phenomena involved, the proposed model has a high degree of empiricism, whether it is to take into account erosion, sticking or transport phenomena within the ice layer. Much work remains to be done to improve the model and reduce empiricism. Ongoing work is on rewriting the erosion mass rate model in terms of dimensionless numbers (using impact angle, particle kinetic energy and ice layer cohesion energy). In particular, future versions of the models for erosion and sticking efficiency will have to include the influence of the ice particle diameter since it has a significant effect on accretion (Knezevici et al., 2012, 2013).

Through experiments conducted by NRC's icing team (Currie et al., 2014), the various adjustable model parameters have been calibrated to ensure that the model is capable of reproducing a large number of tests with acceptable accuracy for applications and without further parameter modification. In particular, the model makes it possible to account for the existence of a "plateau" in terms of melting ratios for which the rate of ice growth is maximum. Another important contribution of the model is its ability to predict conical accretion shapes due to erosion that are never found in normal icing conditions (supercooled water icing).

In the meantime, the models have been validated under mixed-phase conditions on the basis of the experiments conducted at TU Braunschweig in the framework of HAIC (Baumert et al., 2018).

\section{Acknowledgements}

The research leading to this paper has received funding from the European Union's Seventh Framework Programme for research, technological development and demonstration under grant agreement \#ACP2-GA-2012314314 .

\section{Appendix A. Computational setup and model calibration}

Appendix A.1. Computational setup

The simulations have been performed with a 2D solver by considering the midspan shape of the test article. Figure A.11(a) shows the clean crowned 
cylinder profile used in the study. The chord length is $35.2 \mathrm{~cm}$. A C-grid topology (see Fig. A.11(b)) has been used with a farfield boundary condition at the outer bound. Figure A.11(c) shows the aerodynamic flow field (pressure) computed with the inviscid flow solver EULER2D. Figure A.11(d) shows the ice particle trajectories colored by the mass mean diameter $D_{43}$ and computed with the Lagrangian trajectory solver TRAJL2D. The post impact secondary particles are created after the shattering of the impacting particles on the body. They are computed in agreement with the models described in Trontin et al. (2016). They have not been taken into account in this study.

Space (grid) and time (influence of the number of time steps N, see Sec. 2) convergence studies have been carried out for run\#67. The adjustable parameters used in the models are the ones defined from the calibration section (Eq. (A.2)). Figure A.12 shows the ice shapes obtained from the numerical computations for different grids (64, 128 and 256 nodes on the profile, Fig. A.12(a)). For each computation, $N=100$ was selected for the temporal discretization. Note that for the case with 128 nodes on the profile, two kinds of grids have been used: one with a uniform repartition of the nodes along the profile (called 128/uniform grid) and the other one where the leading edge is refined (called 128/refined grid, see Fig. A.12(b)). Figure A.12(a) shows that 128 nodes on the profile with a grid refinement near the stagnation point are enough to compute accurately the ice shape. Using the 128/refined grid, the influence of the number of steps $N$ necessary in the multistep methodology has also been studied. Figure A.13 shows the influence of $N$ (from $N=10$ to $N=200$ ) on the computed ice shapes. Only 50 steps are necessary to compute accurately the ice shape, except near the stagnation point where 100 steps are necessary. The use of 200 steps does not provide any further improvement on the prediction of the ice shape. Given these results, a 128/refined grid with $N=100$ for the multistep approach has been used in all the computations presented in the rest of the paper.

Appendix A.2. Calibration of the model for the sticking efficiency $\epsilon_{s}$

The constant $K^{\#}$ in the expression of the sticking efficiency (Eq. (11)) has been obtained from the Currie et al. (2014) experiments. It is shown that for a crowned cylinder, the stagnation point sticking efficiency is a function of the particle melting ratio $\eta_{m}$ (see Fig. A.14). In the experiments, the apparent local sticking efficiency actually results from the competition between two independant phenomena: the accretion of new incoming ice crystals and the 


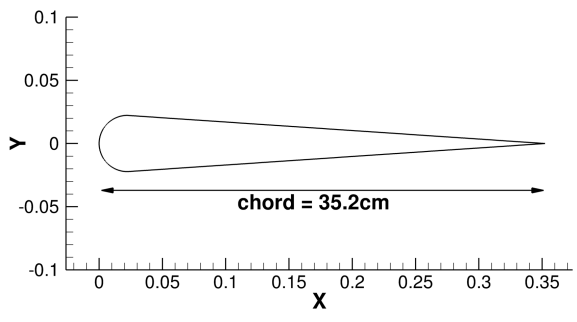

(a)

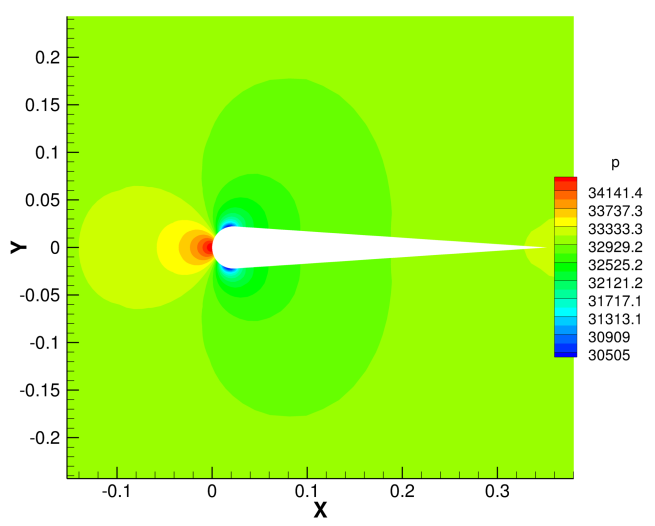

(c)

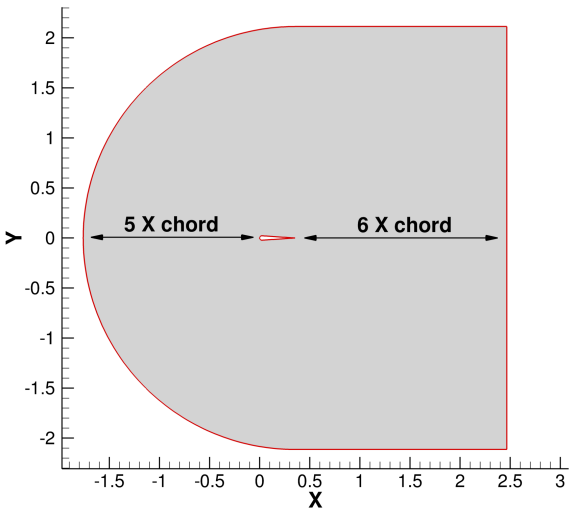

(b)

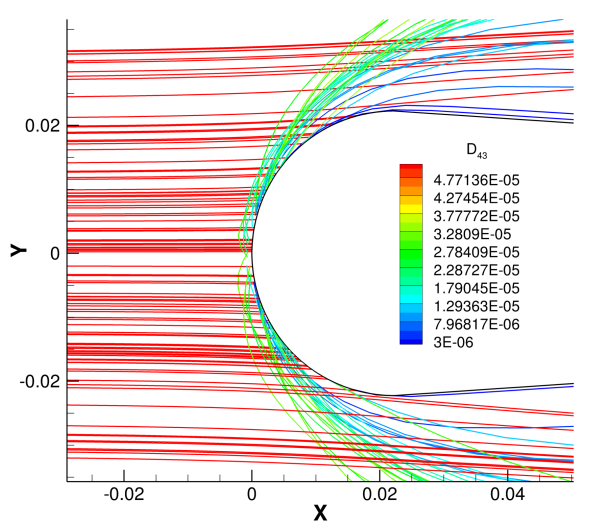

(d)

Figure A.11: Crowned cylinder (see Fig. 4). Main outputs from the MESH2D, AERO2D and TRAJ2D solvers of IGLOO2D (see Fig. 3). (a): clean profile ; (b): C-grid topology ; (c): aerodynamic flow field (pressure) ; (d): ice particle trajectories colored by the diameter $D_{43}$. 


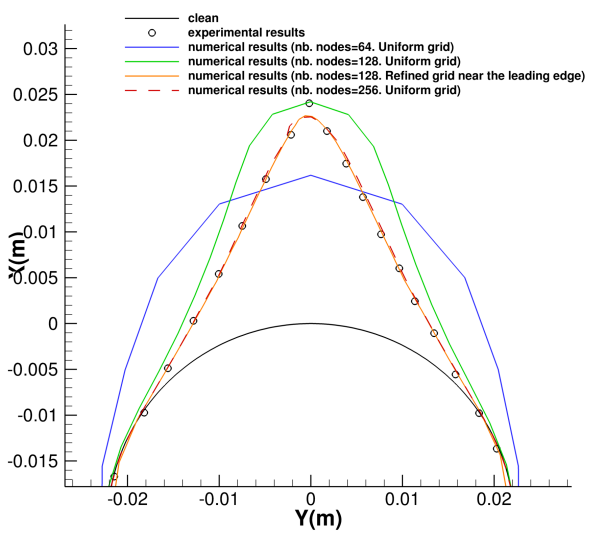

(a)

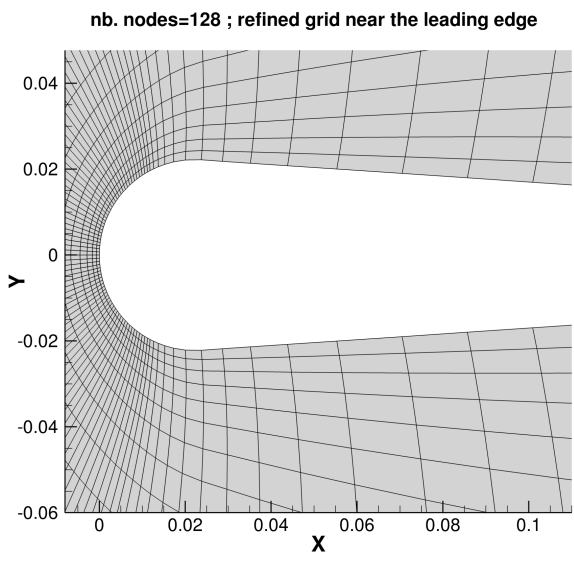

(b)

Figure A.12: (a): space (grid) convergence. Two kinds of grids are presented: "uniform grids" with a uniform repartition of the nodes along the profile and "refined grids" where the leading edge is refined. Several mesh sizes are used with 64, 128 and 256 nodes on the profile. (b): the 128/refined grid is presented.

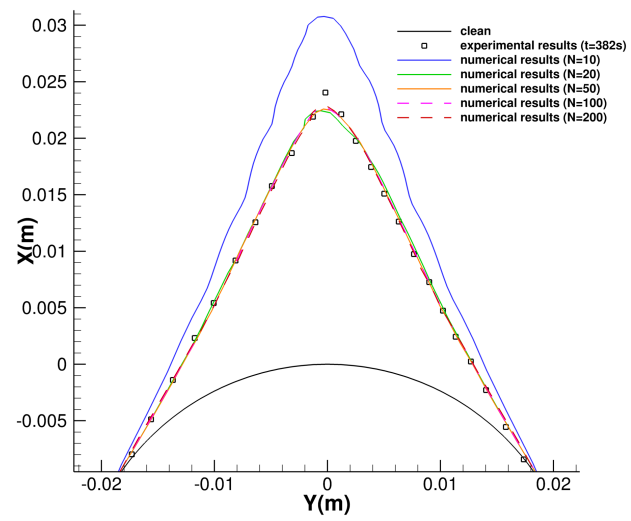

Figure A.13: Influence of the number of steps $N$ (see Eq. (15)) on the ice shape. The $128 /$ refined grid is used. Finally, a 128/refined grid with $N=100$ for the multistep approach is used in all the computations presented in this paper. 


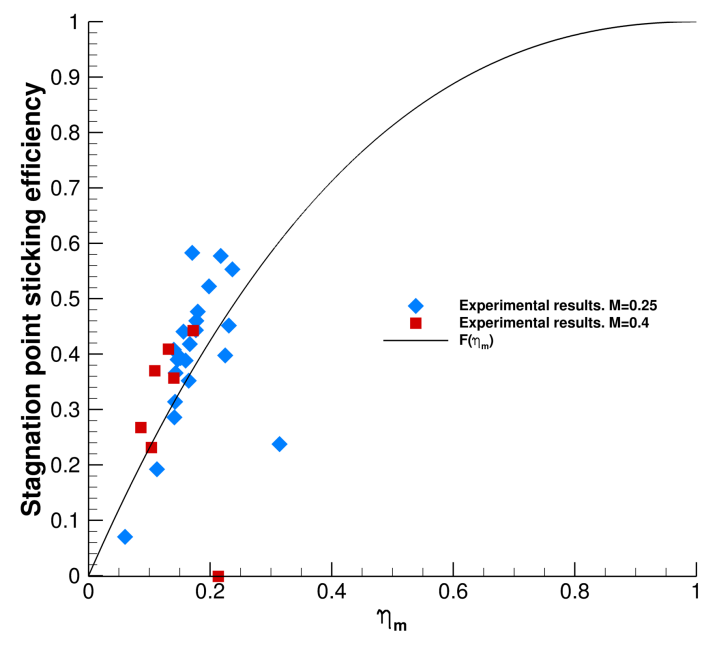

Figure A.14: Crowned cylinder (see Fig. 4). Stagnation point sticking efficiency variation with $\eta_{m}$ at $M_{0}=0.25$ and $M_{0}=0.4 . P_{0}=34.5 \mathrm{kPa}$ (Currie et al., 2014). The function $F$ is plotted with $K^{\#}=2.5$ (Eq. (11)).

erosion of the accreted ice layer by impinging particles. At numerical level, each of these phenomena can be described separately. This is not the case for the experimental observations where only the apparent sticking efficiency is measurable, which combines both the partial sticking of the ice particles and the erosion effects. However, the erosion rate depending mainly on the tangential impact velocity, it is minimum near the stagnation point where the velocity is mainly normal to the wall. Therefore, near the stagnation point, the experimental observations from Currie et al. (2014) can be used to estimate $K^{\#}$ (Eq. (11)), at least at early times. Taking into account the results from Fig. A.14 (issued from Currie et al. (2014)) gives:

$$
K^{\#}=2.5
$$


Appendix A.3. Calibration of the erosion model. Parameters $l_{0}, E$ and $y_{l 0}$

The choice for $l_{0}, E$ and $y_{l 0}$ has been determined after several guesses based on computations with run\#67:

$$
\left\{\begin{aligned}
l_{0} & =l_{0, o p t}=0.015 c \\
E & =E_{o p t}=0.3 \\
y_{l 0} & =y_{l 0, o p t}=0.6
\end{aligned}\right.
$$

where $c$ is the cylinder diameter. In this section, an estimation of the influence of a relative variation of the parameters $l_{0}, E$ and $y_{l 0}$ on the ice shape as well as a validation of the values retained in Eq. (A.2) are proposed.

Regarding the threshold curvature $\kappa_{0}=l_{0}^{-1}$, the length $l_{0}$ may be interpreted as the onset length scale below which erosion smoothing occurs. It is expected to depend on the characteristic length scale of the model. $l_{0}$ is expected to be much lower than the cylinder radius since the erosion smoothing effect does not play any role at this macroscopic scale. Therefore, as far as only the primary stage of the accretion process is concerned, the local curvature $\kappa$ of the ice layer surface is such as $\kappa \ll \kappa_{0}$ and it is possible to replace the erosion model (Eq. (13)) by :

$$
\epsilon_{e r}=E\left(\frac{V_{i m p, c}^{t}}{V_{0}}\right)^{2} \cdot \frac{y_{l 0}}{y_{l 0}-\min \left(y_{l}, y_{l 0}\right)}
$$

To justify this assumption, the dimensionless local curvature (absolute value) $|\kappa|$ along the iced profile is represented in Fig. A.15. At early times $(t=31 \mathrm{~s}$, Fig. A.15, left), $|\kappa| \cdot l_{0} \leq 0.48$ on the whole profile, which justifies a posteriori the previous hypothesis $\left(\kappa \ll \kappa_{0}\right)$ leading to Eq. (A.3). At moderate times $(t=148 \mathrm{~s}$, Fig. A.15, right) and except in the very near region of the stagnation point where $|\kappa| \cdot l_{0} \approx 2.0$, the approximation $\kappa \ll \kappa_{0}$ leading to Eq. (A.3) is justified elsewhere on the iced profile. In Fig. A.16, the influence of $l_{0}\left(l_{0}=l_{l 0, \text { opt }} \pm 25 \%\right)$ is studied at $t=31 \mathrm{~s}$ and $t=148 \mathrm{~s}$, the parameters $E$ and $y_{l 0}$ being set to the values in Eq. (A.2). As expected, the final ice shape is not influenced by $l_{0}$ at early times. At moderate times $(t=148 \mathrm{~s})$, differences are observed near the stagnation point whereas the ice shape far from the stagnation point shows a conical shape which does not depend on the smoothing parameter $l_{0}$. Thus, it is possible to study independently the influences of $E$ and $y_{l 0}$ on the one hand and $l_{0}$ on the other hand. The calibration of $E$ and $y_{l 0}$ has been performed by comparing the numerical ice shapes with the experimental ones at the beginning of the accretion process 

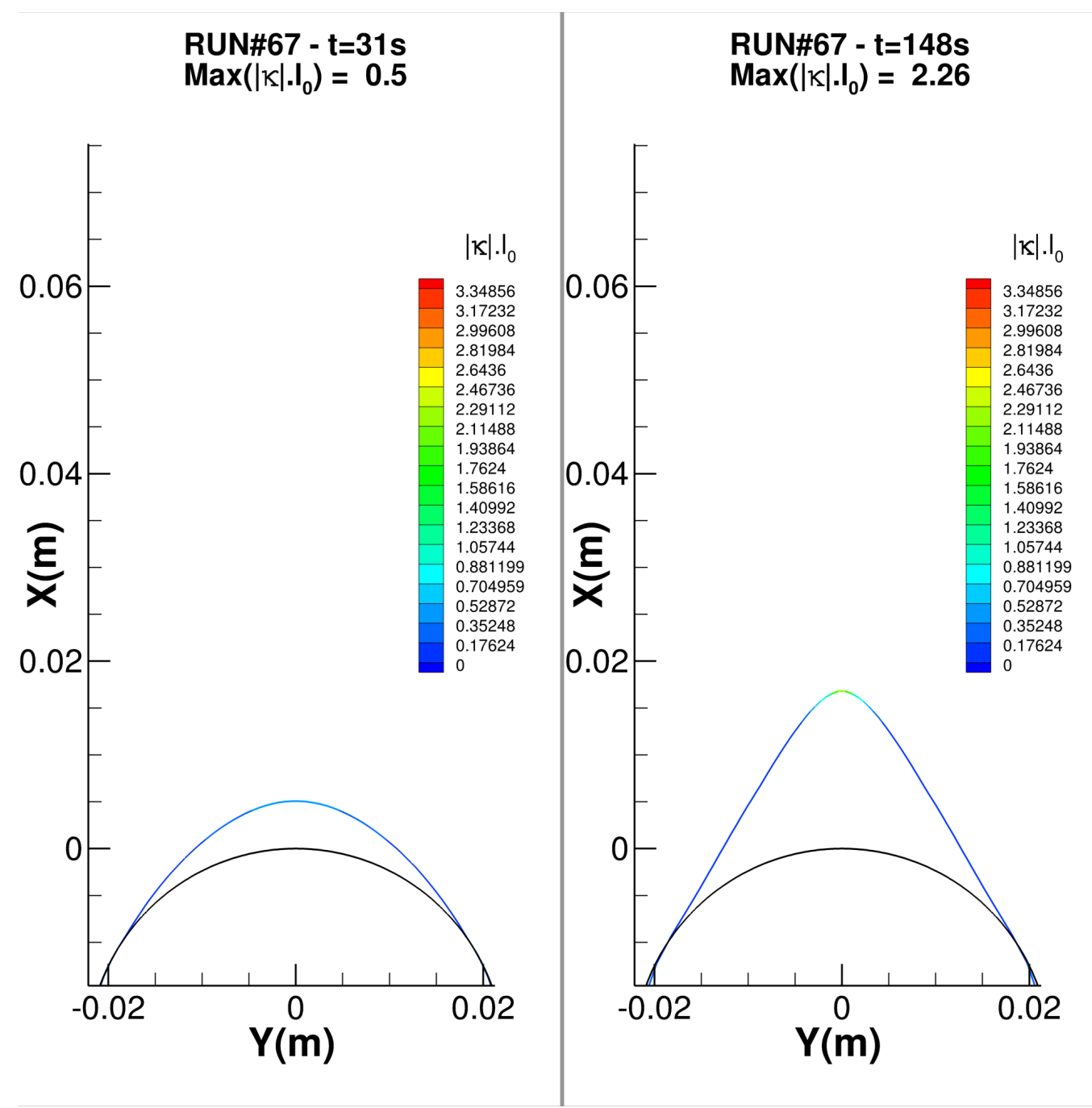

Figure A.15: Run\#67. Dimensionless curvatures of the ice layer surface at early ( $t=31 \mathrm{~s})$ and moderate $(t=148 \mathrm{~s})$ spray times. $E=E_{\text {opt }}, y_{l 0}=y_{l 0, o p t}$ and $l_{0}=l_{0, o p t}$. At early and moderate times, and except in the very near region of the stagnation point, the approximation $\kappa \ll \kappa_{0}\left(\kappa \cdot l_{0} \ll 1\right)$ is justified which leads to the simplified version of the erosion model (Eq. (A.3)). 


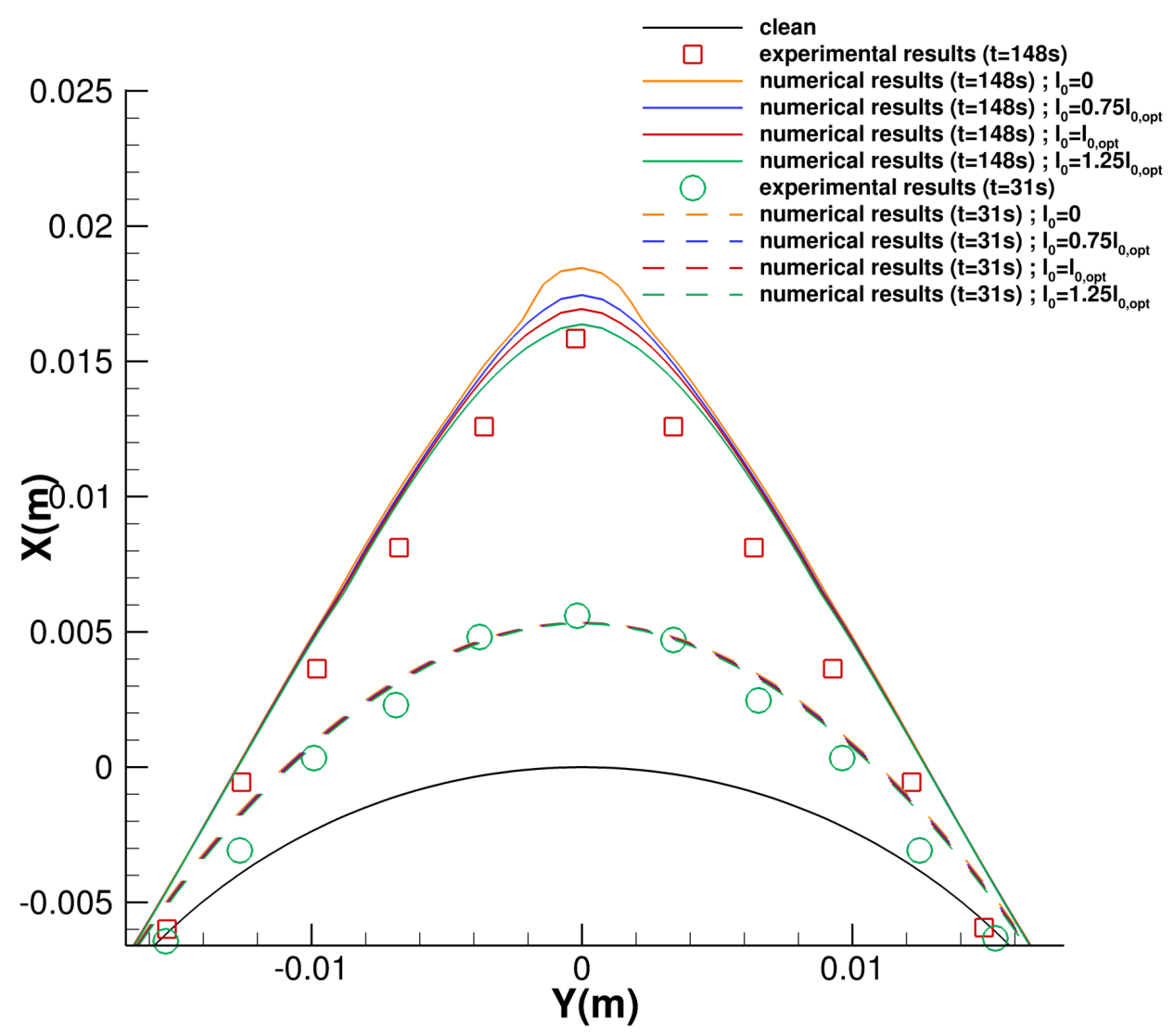

Figure A.16: Run\#67. Influence of $l_{0}\left(l_{0}=l_{l 0, \text { opt }} \pm 25 \%\right)$ at $t=31 \mathrm{~s}$ (early time) and $t=148 \mathrm{~s}$ (moderate time). $E=E_{\text {opt }}$ and $y_{l 0}=y_{l 0, o p t}$. At early and moderate times, the ice shape far from the stagnation point shows a conical shape which does not depend on the smoothing parameter $l_{0}$. 
(early and moderate times) far from the stagnation point. Later times have been used for the calibration of $l_{0}$.

\section{Appendix A.3.1. Calibration of $E$ and $y_{l 0}$}

Figure A.17 shows such a comparison at $t=31 \mathrm{~s}$ and $t=148 \mathrm{~s}$ for different values of $E\left(E=0.75 E_{\text {opt }}, E=E_{\text {opt }}\right.$ and $\left.E=1.25 E_{\text {opt }}\right)$ and $y_{l 0}$ $\left(y_{l 0}=0.75 y_{l 0, o p t}, y_{l 0}=y_{l 0, \text { opt }}\right.$ and $\left.y_{l 0}=1.25 y_{l 0, \text { opt }}\right)$, the parameter $l_{0}$ being set to $l_{l 0, \text { opt }}$. At $t=31 \mathrm{~s}$, the influence of $E$ and $y_{l 0}$ on the ice shape is not conclusive. For a given $y_{l 0}$, the influence of $E$ is low whereas the influence of $y_{l 0}$ at a given $E$ is more significant. At early times ( $\leq 31 \mathrm{~s}$ ), the ice shape remains influenced by the initial cylindrical shape of the clean profile. Therefore, the impinging particle velocity is almost normal to the wall and the corresponding erosion rate is low (Eq. (A.3)). At moderate times $(t=148 \mathrm{~s})$, far from the stagnation point, the configuration $\left(E=E_{\text {opt }} ; y_{l 0}=y_{l 0, \text { opt }}\right)$ is the more accurate (Fig. A.17). This remains true near the stagnation point.

It is worth noticing that $E$ has a strong influence on the cone angle and that the accretion rate is largely overestimated (Fig. A.18) when the erosion model is switched off $(E=0)$.

\section{Appendix A.3.2. Calibration of $l_{0}$}

If the numerical simulation of run\#67 is continued until $t=382 \mathrm{~s}$, the results presented in Fig. A.19 are obtained. Moderate times $(t=148 \mathrm{~s})$ are shown again for the record. It can be seen that a thin unphysical dendritic ice shape is formed at the stagnation point for $l_{0}=0$. This anomalous protuberance cannot be smoothed by the erosion effects since only the tangential velocity (which is close to 0 in the vicinity of the stagnation point) is involved in the erosion model of Eq. (13). Hence a finite value to $l_{0}$ must be given to enforce the regularizing effect of the term $\left[1+\left(l_{0} \kappa\right)^{2}\right]$ in the vicinity of the stagnation point. At moderate times $(t=148 \mathrm{~s})$, the more accurate numerical results compared to the experimental ones are obtained for $l_{0}=1.25 l_{0, \text { opt }}$. At larger times $(t=382 \mathrm{~s})$, they are obtained for $l_{0}=0.75 l_{0, \text { opt }}$. Therefore, $l_{0}=l_{0, \text { opt }}$ has been taken on.

\section{Appendix A.4. Influence of the mass mean diameter $D_{43}$}

The influence of the particle mass mean diameter $D_{43}$ is studied in Fig. A.20 at $t=382 \mathrm{~s}$. Three different particle size distributions (PSD) are compared (see 3): 


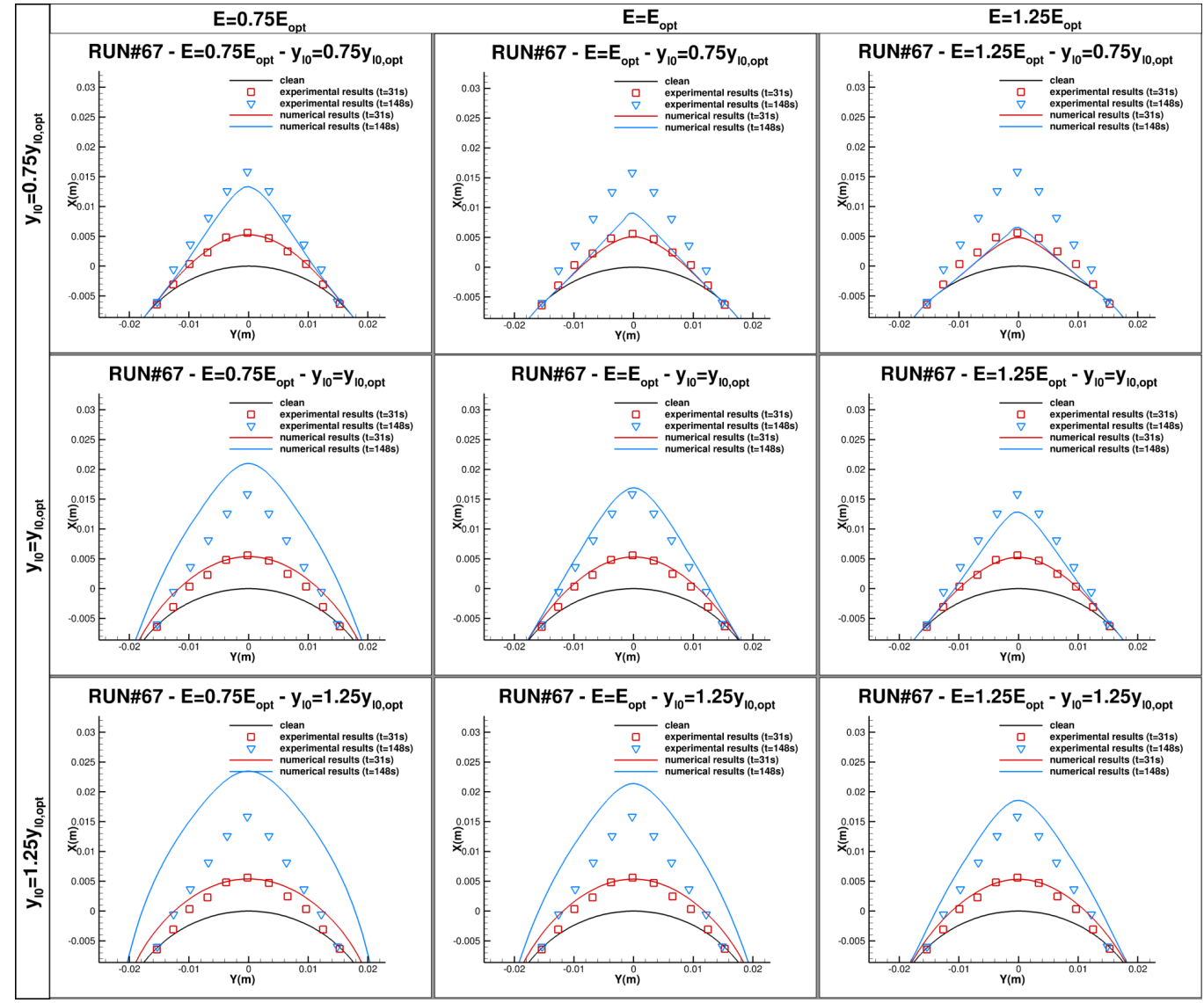

Figure A.17: Calibration of the erosion model (run\#67). Influence of the parameters $E$ and $y_{l 0}$ at early $(t=31 \mathrm{~s})$ and moderate $(t=148 \mathrm{~s})$ times. Sensitivity analysis: $E=E_{o p t} \pm 25 \%$ and $y_{l 0}=y_{l 0, o p t} \pm 25 \%$. $E_{\text {opt }}$ and $y_{l 0, o p t}$ are defined in Eq. (A.2). The parameter $l_{0}$ is set to $l_{l 0, \text { opt }}$ (Eq. (A.2)). 


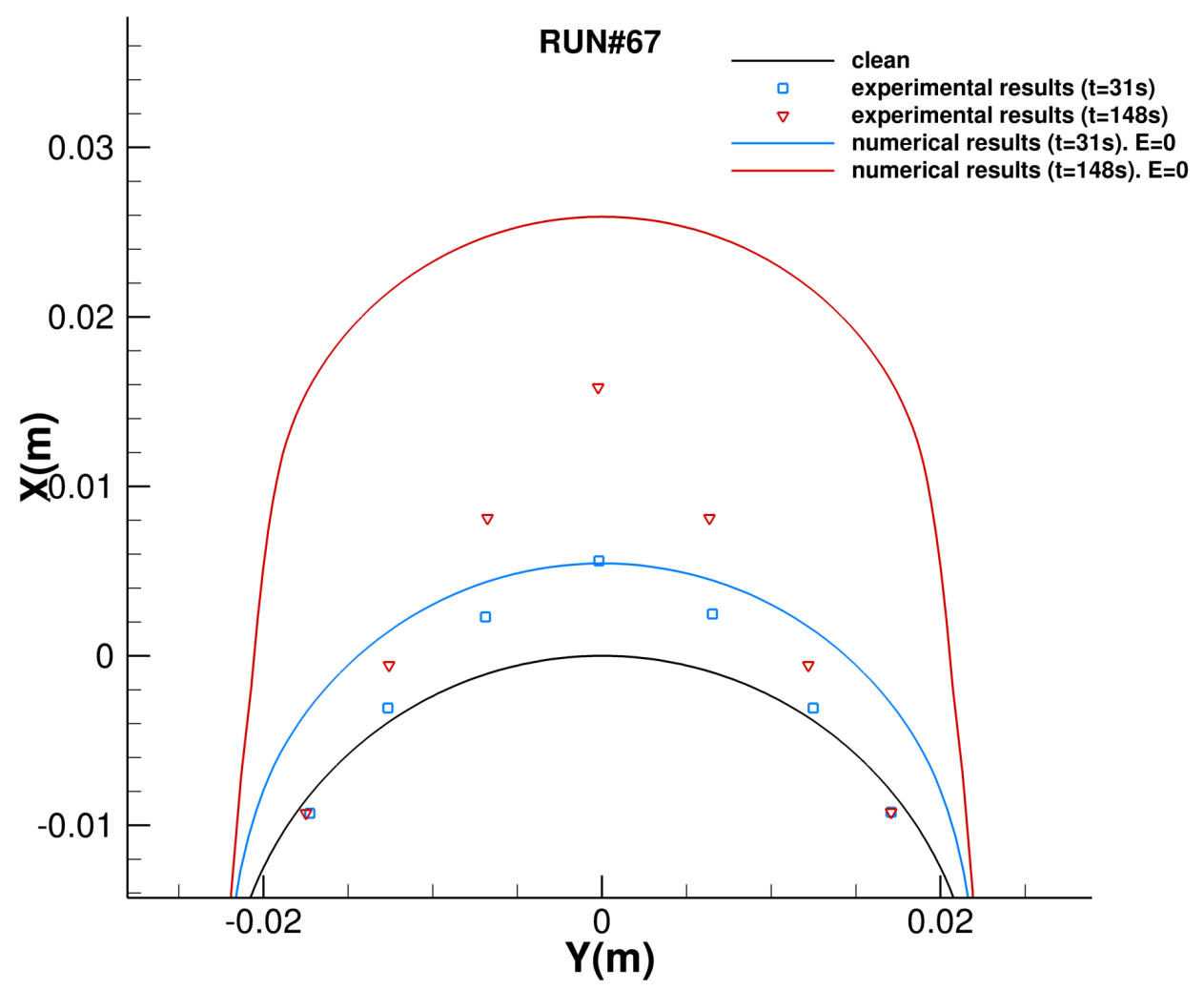

Figure A.18: Calibration of the erosion model (run\#67). Influence of the activation of the erosion model at early $(t=31 \mathrm{~s})$ and moderate $(t=148 \mathrm{~s})$ times. $E$ (Eq. (13)) has a strong influence on the cone angle and the accretion rate is largely overestimated when the erosion model is switched off $(E=0)$. 


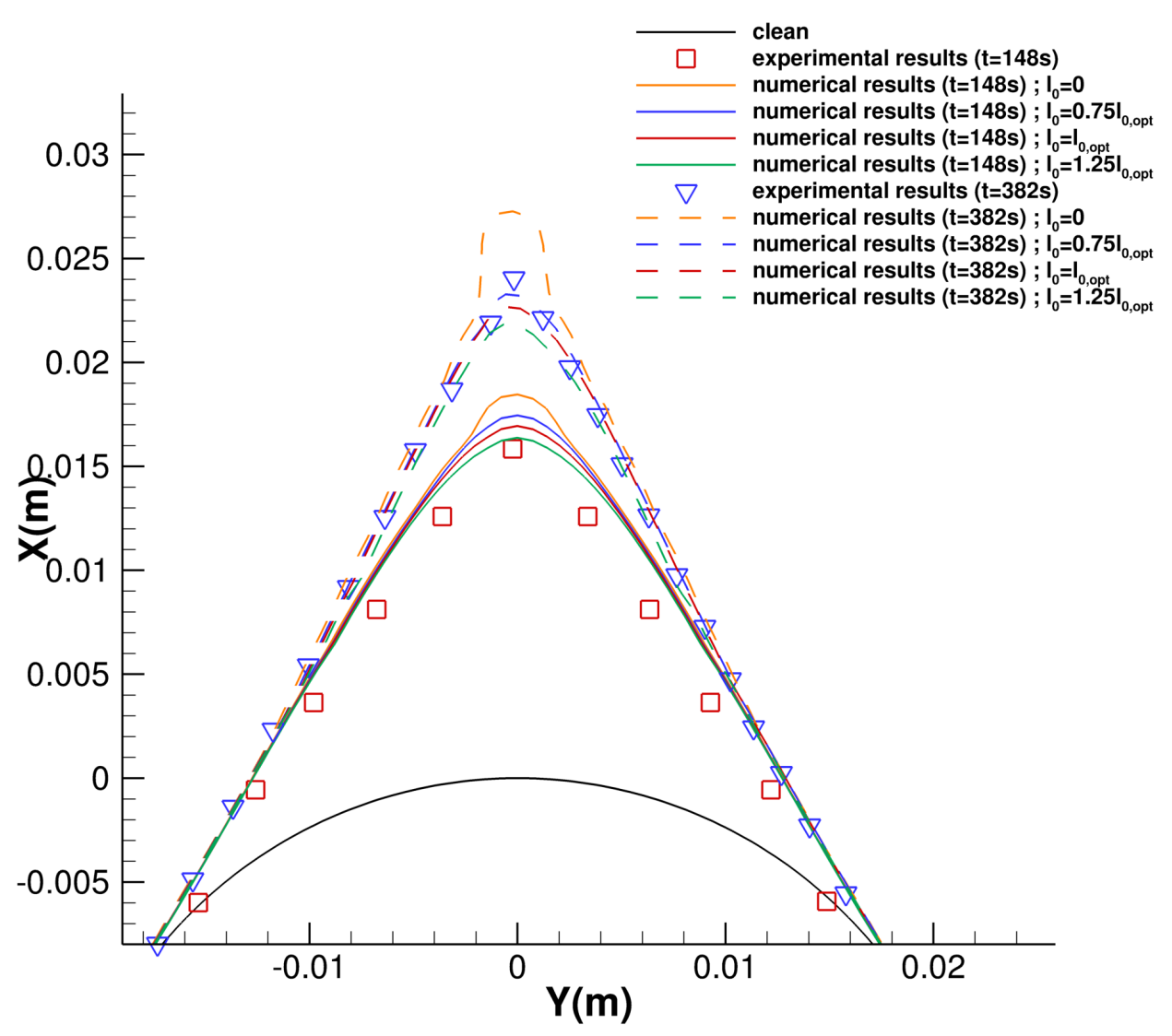

Figure A.19: Calibration of the erosion model (run\#67). Influence of the parameter $l_{0}$ at moderate $(t=148 \mathrm{~s})$ and large $(t=382 \mathrm{~s})$ times. Sensitivity analysis: $l_{0}=l_{l 0, \text { opt }} \pm 25 \%$. $l_{l 0, o p t}$ is defined in Eq. (A.2). The parameters $E$ and $y_{l 0}$ are respectively set to $E_{\text {opt }}$ and $y_{l 0, o p t}$ (Eq. (A.2)). 


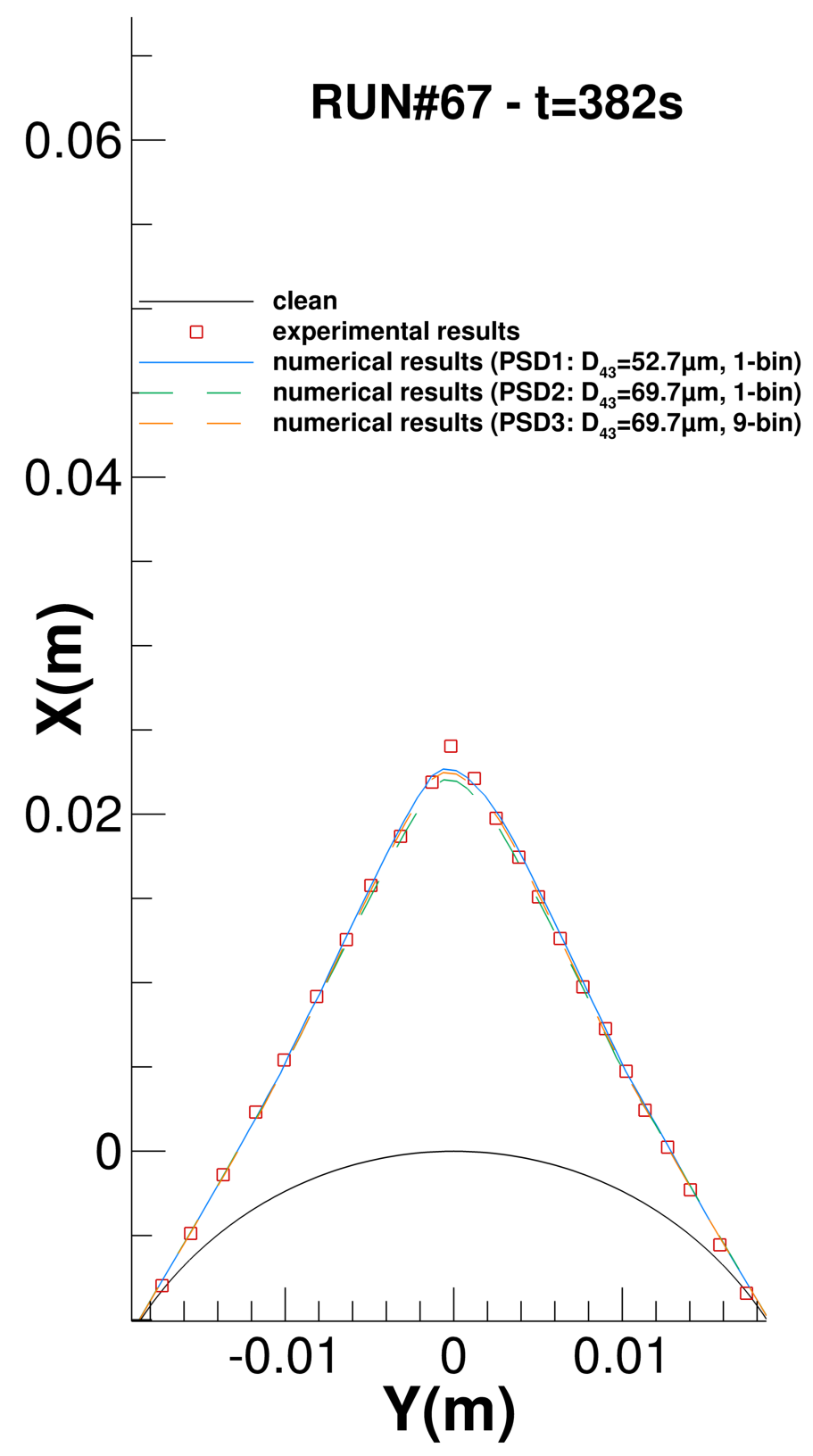

Figure A.20: Influence of the particle mass mean diameter $D_{43}$ (run\#67) at large times $\left(t=382 \mathrm{~s}\right.$ ). Two diameters are compared: $D_{43}=52.7 \mu \mathrm{m}$ (from Currie et al. (2014), blue solid line) and $D_{43}=69.7 \mu \mathrm{m}$ (revisited, from Currie et al. (2015), green and orange dashed lines). For the revised distribution $\left(D_{43}=69.7 \mu \mathrm{m}\right)$, both the 1-bin (green dashed line) and the 9-bin (orange dashed line) are represented. The computed ice shapes are similar. 
- PSD1: the 1-bin distribution derived from the 7-bins distribution proposed in Currie et al. (2014) so that $D_{43}=52.7 \mu \mathrm{m}$ (blue solid line, Fig. A.20).

- PSD2: the 1-bin distribution derived from the revised 9-bin distribution detailed in Currie et al. (2015) so that $D_{43}=69.7 \mu \mathrm{m}$ (green dashed line, Fig. A.20).

- PSD3: the revised 9-bin distribution itself detailed in Currie et al. (2015) so that $D_{43}=69.7 \mu \mathrm{m}$ (orange dashed line, Fig. A.20).

The numerical ice shapes obtained with PSD1 and PSD2 are very close which confirms the weak dependency of the final ice shapes on the particle size distribution uncertainties. Indeed, neither the erosion (Eq. (13)) nor the sticking efficiency (Eq. (10)) models depend on the particle diameter. As far as particle trajectories are concerned, $D_{43}$ has an influence but, here, since $D_{43}$ is quite large, trajectories are almost ballistic and the influence of $D_{43}$ remains limited (Fig. A.11(d)). Regarding PSD2 and PSD3, $D_{43}=69.7 \mu \mathrm{m}$ for both distributions and the computed ice shapes are similar. Since the computational cost is quite larger for the 9-bin distribution than for the 1bin distribution, this justifies why all the computations in this paper have been done with the 1-bin distribution PSD1. 
Al-Khalil, K., Irani, E., Miller, D., 2003. Mixed phase icing simulation and testing at the Cox icing wind tunnel. In: 41st Aerospace Sciences Meeting and Exhibit, Aerospace Sciences Meetings, AIAA-2003-903, Reno, USA.

Ayan, E., Ozgen, S., Murat, C., Tarhan, E., 2015. Prediction of ice crystal accretion with taice. In: SAE 2015 International Conference on Icing of Aircraft, Engines, and Structures, SAE 2015-01-2148.

Baumert, A., Bansmer, S., Trontin, P., Villedieu, P., 2018. Experimental and numerical investigations on aircraft icing at mixed phase conditions. International Journal of Heat and Mass Transfer 123, 957-978.

Bennani, L., 2014. Two dimensional modelling of electrothermal ice protection systems. Ph.D. thesis, Institut Supérieur de l'Aéronautique et de l'Espace (ISAE).

Bennani, L., Villedieu, P., Salaun, M., Trontin, P., 2014. Numerical simulation and modeling of ice shedding: Process initiation. Computers \& Structures 142, 15-27.

Bravin, M., Strapp, J. W., Mason, J. G., 2015. An investigation into location and convective lifecycle trends in an ice crystal icing engine event database. In: SAE 2015 International Conference on Icing of Aircraft, Engines, and Structures, 2015-01-2130, Prague, Czech Republic.

Civil Aviation Authority of New Zealand, 2000. Aircraft Icing Handbook.

Currie, T. C., Fuleki, D. M., 2015. Development and application of an impedance-based instrument for measuring the liquid fraction and thickness of ice crystal accretions. In: SAE 2015 International Conference on Icing of Aircraft, Engines, and Structures, 2015-01-2134, Prague, Czech Republic.

Currie, T. C., Fuleki, D. M., 2016. Experimental results for ice crystal icing on hemispherical and double wedge geometries at varying mach numbers and wet bulb temperatures. In: 8th AIAA Atmospheric and Space Environments Conference, AIAA-2016-3740.

Currie, T. C., Fuleki, D. M., Davison, C., 2015. Simulation of ice particle melting in the NRCC RATFac mixed-phase icing tunnel. In: SAE 2015 
International Conference on Icing of Aircraft, Engines, and Structures, 2015-01-2107, Prague, Czech Republic.

Currie, T. C., Fuleki, D. M., Knezevici, D. C., MacLeod, J. D., 2013. Altitude scaling of ice crystal accretion. In: 5th AIAA Atmospheric and Space Environments Conference, AIAA-2013-2677, Orlando, USA.

Currie, T. C., Fuleki, D. M., Mahallati, A., 2014. Experimental studies of mixed-phase sticking efficiency for ice crystal accretion in jet engines. In: 6th AIAA Atmospheric and Space Environments Conference, AIAA-20143049 .

Currie, T. C., Struk, P. M., Tsao, J. C., Fuleki, D. M., Knezevici, D. C., 2012. Fundamental study of mixed-phase icing with application to ice crystal accretion in aircraft jet engines. In: 4th AIAA Atmospheric and Space Environments Conference, AIAA-2012-3035.

Fluid Dynamics Panel Working Group 20, 1997. Agard advisory report 344 - ice accretion simulation. Tech. rep., AGARD (Advisory Group for Aerospace Research \& Development).

Goodwin, R. V., Dischinger, D. G., 2014. Turbofan ice crystal rollback investigation and preparations leading to inaugural ice crystal engine test at NASA PSL-3 test facility. In: 6th Atmospheric and Space Environments Conference, AIAA-2014-2895, Atlanta, USA.

Griffin, T. A., Dicki, D. J., Lizanich, P. J., 2014. PSL icing facility upgrade overview. In: 6th AIAA Atmospheric and Space Environments Conference, AIAA-2014-2896, Atlanta, USA.

Habashi, W. G., Nilamdeen, M. S., 2011. Multiphase approach toward simulating ice crystal ingestion in jet engines. Journal of Propulsion and Power 27 (5), 959-969.

Hauk, T., 2015. Investigation of the impact and melting process of ice particles. Ph.D. thesis, Technische Universität Darmstadt.

Hauk, T., Bonaccurso, E., Roisman, I. V., Tropea, C., 2015. Ice crystal impact onto a dry solid wall. particle fragmentation. In: Proc. R. Soc. A. Vol. 471. The Royal Society, p. 20150399. 
Hauk, T., Bonaccurso, E., Villedieu, P., Trontin, P., 2016. Theoretical and experimental investigation of the melting process of ice particles. J. of Thermophysics and Heat Transfer 30 (4), 946-954.

Hauk, T., Roisman, I. V., Tropea, C., 2014. Investigation of the melting behaviour of ice particles in an acoustic levitator. In: 11th AIAA/ASME Joint thermophysics and heat transfer conference, Atlanta, USA.

Iuliano, E., Montreuil, E., Norde, E., Van der Weide, E. T. A., Hoeijmakers, H. W. M., 2015. Modelling of non-spherical particle evolution for ice crystals simulation with an eulerian approach. In: SAE 2015 International Conference on Icing of Aircraft, Engines, and Structures, SAE 2015-012138.

Kintea, D. M., Roisman, I. V., Tropea, C., 2016. Transport processes in a wet granular ice layer: Model for ice accretion and shedding. International Journal of Heat and Mass Transfer 97, 461-472.

Knezevici, D. C., Fuleki, D. M., Currie, T. C., Galeote, B., Chalmers, J. L. Y., MacLeod, J. D., 2013. Particle size effects on ice crystal accretionpart ii. In: 5th AIAA Atmospheric and Space Environments Conference, AIAA-2013-2676. pp. 24-27.

Knezevici, D. C., Fuleki, D. M., Currie, T. C., MacLeod, J. D., 2012. Particle size effects on ice crystal accretion. In: 4th AIAA Atmospheric and Space Environments Conference, AIAA-2012-3039. Vol. 10. pp. 6-2012.

Lozowski, E. P., Stallabrass, J. R., Hearty, P. F., 1979. The icing of an unheated non-rotating cylinder in liquid water droplet-ice crystal clouds. National Research Council Canada, Division of Mechanical Engineering.

Mason, J. G., Chow, P., Fuleki, D. M., 2011. Understanding ice crystal accretion and shedding phenomenon in jet engines using a rig test. Journal of Engineering for Gas Turbines and Power 133 (4), 041201-1-8.

Mason, J. G., Strapp, J. W., Chow, P., 2006. The ice particle threat to engines in flight. In: 44th AIAA Aerospace Sciences Meeting, AIAA-2006206, Reno, Nevada, USA. 
Mazzawy, R. S., 2007. Modeling of ice accretion and shedding in turbofan engines with mixed phase/glaciated (ice crystal) conditions. Tech. rep., SAE Technical Paper.

Messinger, B. L., 1953. Equilibrium temperature of an unheated icing surface as a function of air speed. Journal of the aerospace sciences 20, 29.

Miller, D. R., Bond, T. H., Sheldon, D. W., Wright, W. B., Langhals, T., Al-Khalil, K. M., Broughton, H., 1997. Validation of NASA thermal ice protection computer codes. part 1; program overview. In: 35th Aerospace Sciences Meeting and Exhibit, AIAA-97-0049, Reno, USA.

Rios Pabon, M. A., 2012. Ice crystal ingestion by turbofans. Ph.D. thesis, Drexel University.

Roisman, I. V., Tropea, C., 2015. Impact of a crushing ice particle onto a dry solid wall. Proc. R. Soc. A 471: 20150525.

Struk, P. M., Currie, T. C., Wright, W. B., Knezevici, D. C., Fuleki, D. M., Broeren, A. P., Vargas, M., Tsao, J. C., 2011. Fundamental ice crystal accretion physics studies. In: SAE International Icing Conference, SAE 2011-38-0018.

Trontin, P., Blanchard, G., Villedieu, P., 2016. A comprehensive numerical model for mixed-phase and glaciated icing conditions. In: 8th AIAA Atmospheric and Space Environments Conference, AIAA-2016-3742.

Trontin, P., Kontogiannis, A., Blanchard, G., Villedieu, P., 2017. Description and assessment of the new onera $2 \mathrm{~d}$ icing suite igloo2d. In: 9th AIAA Atmospheric and Space Environments Conference, AIAA-2017-3417, Denver, USA.

Villedieu, P., Trontin, P., Chauvin, R., 2014. Glaciated and mixed phase ice accretion modeling using ONERA 2D icing suite. In: 6th AIAA Atmospheric and Space Environments Conference, AIAA-2014-2199, Atlanta, USA.

Wright, W. B., Jorgenson, P. C. E., Veres, J. P., 2010. Mixed phase modeling in glennice with application to engine icing. In: AIAA Atmospheric and Space Environments Conference, AIAA-2010-7674. 